Signalling

Elsevier Editorial System(tm) for Cellular

Manuscript Draft

Manuscript Number: CLS-D-16-00164R1

Title: The protein phosphatase 4 - PEA15 axis regulates the survival of breast cancer cells

Article Type: Full Length Article

Keywords: PP4; PP4C; Breast cancer; PEA15, Cell survival.

Corresponding Author: Dr. Mirna Mourtada-Maarabouni, PhD

Corresponding Author's Institution: Keele University

First Author: Hiba N Mohammed, MD

Order of Authors: Hiba N Mohammed, MD; Mark R Pickard, PhD; Mirna Mourtada-Maarabouni, PhD

Abstract: Background

The control of breast cell survival is of critical importance for preventing breast cancer initiation and progression. The activity of many proteins which regulate cell survival is controlled by reversible phosphorylation, so that the relevant kinases and phosphatases play crucial roles in determining cell fate. Several protein kinases act as oncoproteins in breast cancer and changes in their activities contribute to the process of transformation. Through counteracting the activity of oncogenic kinases, the protein phosphatases are also likely to be important players in breast cancer development, but this class of molecules is relatively poorly understood. Here we have investigated the role of the serine/ threonine protein phosphatase 4 in the control of cell survival of breast cancer cells.

Methods

The breast cancer cell lines, MCF7 and MDA-MB-231, were transfected with expression vectors encoding the catalytic subunit of protein phosphatase 4 (PP4C) or with PP4C siRNAs. Culture viability, apoptosis, cell migration and cell cycle were assessed. The involvement of phosphoprotein enriched in astrocytes $15 \mathrm{kD}$ (PEA15) in PP4c action was investigated by immunoblotting approaches and by siRNA-mediated silencing of PEA15.

Results

In this study we showed that PP4C over-expression inhibited cell

proliferation, enhanced spontaneous apoptosis and decreased the migratory and colony forming abilities of breast cancer cells. Moreover, PP4C downregulation produced complementary effects. PP4C is demonstrated to regulate the phosphorylation of PEA15, and PEA15 itself regulates the apoptosis of breast cancer cells. The inhibitory effects of PP4c on breast cancer cell survival and growth were lost in PEA15 knockdown cells, confirming that PP4C action is mediated, at least in part, through the de-phosphorylation of apoptosis regulator PEA15.

Conclusion

Our work shows that PP4 regulates breast cancer cell survival and identifies a novel PP4C-PEA15 signalling axis in the control of breast cancer cell survival. The dysfunction of this axis may be important in the development and progression of breast cancer. 
Response to Reviewers: Reviewers' comments

Strengths and weaknesses

We are pleased that the reviewer considers the work to be well

accomplished and considers it to be worthy of publication. Please find below our response to Reviewers' Comments.

- There is a tendency for repetition, which slightly distracted me (see comments below). However, this is due to the nature of the subject matter. If it can be reduced, that might be useful. I also felt that figures $1 \& 2$ can be merged, as well as Fig 3\&4. A balance has to be struck between clarity and space, but the current layout is not too bad. Response:

Two different breast cancer cell lines MCF7 and MDA-MB-231, were used in the present study. The two cell lines were selected because they represent different breast cancer phenotypes. MCF-7 is a non-invasive cell line that is representative of estrogen-dependent breast cancer, whereas MDA-MB-231 is an invasive, estrogen-independent cell line representative of triple negative breast cancer (TNBC). On the one hand, MCF7 is the most widely studied of the currently available human breast cancer cell lines, hence the reason for its inclusion in the study here. On the other hand, there is currently a major need to identify novel molecular targets for therapy of TNBC (lacks oestrogen receptor, progesterone receptor and HER2 amplification), which can be highly malignant and often exhibits resistance to conventional chemotherapies [i.e. see Engebraaten et al. (2013) Am J Pathol 183:1064-1074]; consequently we believe that it is also important to include data from MDA-MB-231 cells in the full paper. Because the two cell lines are representative of different breast cancer subtypes, we do not believe that it is justified to merge the various Figures. Indeed the reviewer does consider that 'the current layout is not bad'.

Minor amendments, typing errors and suggestions for improved syntax: We apologise for the typing errors - these have been corrected (Please see below). In response to the reviewer's suggestions, the following changes have been made to the manuscript:

-Page 1, Line 8: The activity of many of proteins

This now reads: "the activity of many proteins"

-P 1, L 34-41: Long sentence. Suggest breaking it in L 34 after the word 'sequences' AND P 1, L 39: Missing word 'siRNAs related to...'?

This now reads: "The breast cancer cell lines, MCF7 and MDA-MB-231, were transfected with expression vector encoding the catalytic subunit of protein phosphatase 4 (PP4C) or with PP4C siRNAs. Culture viability, apoptosis, cell migration and cell cycle were assessed."

- $\mathrm{P}$ 4, L 1: Comma between 'HERS' and HER2/Neu

This now reads: "(HERs), HER2/Neu"

-P 4, L 46: Personal preference for 'reverse' instead of 'oppose'. This now reads : "the enzymes that reverse the action of protein kinases, is relatively under-studied"

-P 5, L 51: 'cell line, HEK 293T [22] and' -> 'cell line HEK 293T [22], and'

This now reads; "in the human embryonic kidney cell line HEK 293T [22], and in both leukemic T-cells"

-P 7, L 37: insert 'of' between 'weeks' and 'receipt'

This now reads: "weeks of receipt" 
- P 8, L 3: Remove comma after vector. Perhaps add comma before 'and' to emphasize that pcDNA3.1 is the control

This now reads: "Plasmids were pcDNA3.1-PP4C [23,27], and empty pcDNA3.1 vector as control"

-P 10, L 8: I suspect this formula gives the percent unhealed wound area. Please verify.

The formula has been changed.

- P 13, L 33: 'to control for any' -> 'to control any'

The requested change has been made.

-P 15, Sub-title 3.3 and in subsequent occurrences: Ser116 numbering should not be a superscript.

All Ser116 have been changed to Ser116.

- P 15, L 6: Please remove duplicated 'to be'

The duplicated "to be" has been removed.

-P 16, L 37: I suspect a word needs to be inserted after 'PEA15'. The oncogenic role is not simply its existence but rather its over-activity. Suggest adding the word 'over-expression'.

This now reads "confirming an oncogenic role for PEA-15 over-expression in both oestrogen receptor-positive and TNBC cell lines"

-P 16, L 39: The definition of TNBC should have been made upon first usage on P 12, L 54 .

TNBC is now defined on P12, L54.

-P 16, L 55: 'MCF-7' -> 'MCF7' like all the other occurrences in the manuscript.

All instances of $\mathrm{MCF}-7$ in the text have been changed to MCF7.

- P 17, L 10 \& 12: The same figure/subfigure is referred to in two different contexts. Please amend.

This has been amended and now reads: "Over-expression of PP4C in (-) SiRNA transfected cells decreased the number of viable cells by more than 40\% and enhanced the level of basal apoptosis but had no effect on the number of viable cells and the level of apoptosis in cells which had been previously transfected with PEA-15 siRNA (Figure 9C,D) .

-P 18: The first few lines appear to be very much a repetition of the last 4 lines on P 16

We have changed these lines. This now reads : "Increased in PP4c protein levels in both oestrogen receptor-positive and TNBC cells was associated with the consistent and significant decrease in both short and long term viability and stimulated apoptosis in the absence of extracellular stimuli."

-P 18, L 28: 'PP4C' here is superfluous. Please confirm / remove.

The unnecessary PP4C has been removed.

- P 18, L 45: The sentence starting 'PP4c also plays a role' feels like a repetition.

The sentence has been removed.

- P 19, L 13: Please define what 'sensitizes' means. Does it make cells more sensitive or less sensitive to cisplatin?

This now reads: "inhibition of $\mathrm{PP} 4 \mathrm{C}$ expression increased the sensitivity of breast and lung cancer cells to cisplatin treatment"

-P 19, L 28: 'embryonic kidney human cells' -> 'human embryonic kidney cells'

The change has been made.

-P 20, L 52-60: Very long sentence, with intervening phrases that complicate the context. Suggest writing it as: 'Over-expression of PP4C (which correlated with increased apoptosis and reduced proliferation), caused a significant decrease in the phosphorylation level pf PEA15. 
Conversely, down-regulation of PP4C (which stimulated proliferation and inhibited apoptosis), resulted in ...'

This now reads: "Over-expression of PP4C (which correlated with increased apoptosis and reduced proliferation), caused a significant decrease in the phosphorylation level pf PEA15. Conversely, down-regulation of PP4C (which stimulated proliferation and inhibited apoptosis) prevented the de-phosphorylation of PEA15, leading to an increase in the content of its phosphorylated form at Ser116."

-P 22, L 17: The closing sentence ' These findings ...' is a repetition of a statement on the previous page. The authors need tom decide whether this is the correct place for this statement, or whether to down-play it in previous text.

The statement in P21, L52-57 has been removed and placed on P 22, L 17, before the closing statement.

\section{Comments on 'Discussion'}

In response to the reviewer's comments we have made the following changes to the discussion:

- The interpretation of the results on P 19, starting on L 5, is a typical text for covering all bases. The authors true opinion is not coming through forcefully, as I think it ought to. This is a significant result and there should be strong direction from the authors as to what it means. It feels weak.

To address the reviewer's comments, we have inserted into the paragraph the following statement: "Our study reveals that PP4c endogenous level is of critical importance for the survival and growth of breast cancer cells".

We have also removed potential from the sentence : "point to a potential tumour suppressor function for this protein in breast cancer."

The paragraph now reads:

"Our study reveals that PP4C endogenous level is of critical importance for the survival and growth of breast cancer cells. Modulation of the expression of the catalytic subunit of PP4 was shown to cause significant and specific effects on the survival and proliferation of breast cancer cells. Increased in PP4c protein levels in both oestrogen receptorpositive and TNBC cells was associated with the consistent and significant decrease in both short and long term viability and stimulated apoptosis in the absence of extracellular stimuli. We have also shown that PP4C knockdown caused an increase in the rate of cell proliferation and migration in both cell types. Together, the data support an important role for $\mathrm{PP} 4 \mathrm{C}$ in maintaining the delicate balance between cell survival and cell death in a range of breast cancer cell types and point to a tumour suppressor function for this protein in breast cancer."

- "The statement at the bottom of P 20 'Conversely, down-regulation of PP4C ... resulted in significant elevation ... of phosphorylated Ser116'. This last statement is not accurate. The increased phosphorylation is the result of depleted PP4c, but not caused by it."

Instead of " down-regulation of $\mathrm{PP} 4 \mathrm{C}$.... resulted in significant elevation of phosphorylated Ser116'. We have changed the sentence to "downregulation of ------- prevented the de-phosphorylation of PEA15, leading to an increase in the content of phosphorylated Ser116".

- The comment above is directly linked to the statement on P 21, L 30 . PEA15 is not being switched from tumour suppressor to promoter. I think 
it is better described as a growth factor that needs to be carefully controlled, hence the existence of PP4c.

We appreciate the comments relating to the tumour suppressor/ promotor activity of PEA-15. However, PEA15 has been described in the literature to display tumour suppressor or promoter activity dependent on its phosphorylation state (Please refer to Sulzmaier et al., 2012.

Phosphorylation is the switch that turns PEA-15 from tumour suppressor to tumour promoter. Small GTPases. 2012; 3(3): 173-177). Therefore, we believe that it is justified to use this phrasing in relation to our work on the regulation of PEA15 activity by PP4. 


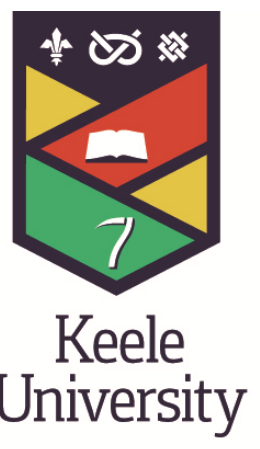

Professor Donald Maurice Co-Editor

Cell Signalling

$10^{\text {th }}$ June 2016

Dear Professor Maurice

In response to your Decision Letter, dated $2^{\text {nd }}$ May 2016, I am submitting a further revised version of the manuscript: 'The protein phosphatase 4 - PEA15 axis regulates the survival of breast cancer cells', by H.N. Mohammed, M.R. Pickard, M. MourtadaMaarabouni, under consideration for publication as full length research article in your journal.

We have addressed the Reviewers' comments and accordingly have revised the manuscript. These revisions comprise changes to the original manuscript, all of which are supplied in the 'Response to Reviewers' document.

We would like to take this opportunity to thank again the reviewers for their constructive comments, and we hope that our amended manuscript is now suitable for publication.

Yours faithfully

Dr M.Mourtada-Maarabouni 


\section{$\underline{\text { Reviewers' comments }}$}

\section{Strengths and weaknesses}

We are pleased that the reviewer considers the work to be well accomplished and considers it to be worthy of publication. Please find below our response to Reviewers' Comments.

- There is a tendency for repetition, which slightly distracted me (see comments below). However, this is due to the nature of the subject matter. If it can be reduced, that might be useful. I also felt that figures $1 \& 2$ can be merged, as well as Fig 3\&4. A balance has to be struck between clarity and space, but the current layout is not too bad.

Response:

Two different breast cancer cell lines MCF7 and MDA-MB-231, were used in the present study. The two cell lines were selected because they represent different breast cancer phenotypes. MCF- 7 is a non-invasive cell line that is representative of estrogen-dependent breast cancer, whereas MDA-MB231 is an invasive, estrogen-independent cell line representative of triple negative breast cancer (TNBC). On the one hand, MCF7 is the most widely studied of the currently available human breast cancer cell lines, hence the reason for its inclusion in the study here. On the other hand, there is currently a major need to identify novel molecular targets for therapy of TNBC (lacks oestrogen receptor, progesterone receptor and HER2 amplification), which can be highly malignant and often exhibits resistance to conventional chemotherapies [i.e. see Engebraaten et al. (2013) Am J Pathol 183:1064-1074]; consequently we believe that it is also important to include data from MDA-MB231 cells in the full paper. Because the two cell lines are representative of different breast cancer subtypes, we do not believe that it is justified to merge the various Figures. Indeed the reviewer does consider that 'the current layout is not bad'.

\section{Minor amendments, typing errors and suggestions for improved syntax:}

We apologise for the typing errors - these have been corrected (Please see below). In response to the reviewer's suggestions, the following changes have been made to the manuscript:

- Page 1, Line 8: The activity of many of proteins

This now reads: "the activity of many proteins"

- $\quad$ P 1, L 34-41: Long sentence. Suggest breaking it in L 34 after the word 'sequences' AND P 1, L 39: Missing word 'siRNAs related to ...'?

This now reads: "The breast cancer cell lines, MCF7 and MDA-MB-231, were transfected with expression vector encoding the catalytic subunit of protein phosphatase 4 (PP4c) or with PP4c siRNAs. Culture viability, apoptosis, cell migration and cell cycle were assessed."

\section{- P 4, L 1: Comma between 'HERS' and HER2/Neu}

This now reads: "(HERs), HER2/Neu" 
- P 4, L 46: Personal preference for 'reverse' instead of 'oppose'.

This now reads : "the enzymes that reverse the action of protein kinases, is relatively under-studied"

- P 5, L 51: 'cell line, HEK 293T [22] and' -> 'cell line HEK 293T [22], and'

This now reads; "in the human embryonic kidney cell line HEK 293T [22], and in both leukemic Tcells"

- P 7, L 37: insert 'of' between 'weeks' and 'receipt'

This now reads: "weeks of receipt"

- P 8, L 3: Remove comma after vector. Perhaps add comma before 'and' to emphasize that pcDNA3.1 is the control

This now reads: "Plasmids were pcDNA3.1-PP4c $[23,27]$, and empty pcDNA3.1 vector as control"

- P 10, L 8: I suspect this formula gives the percent unhealed wound area. Please verify.

The formula has been replaced by :

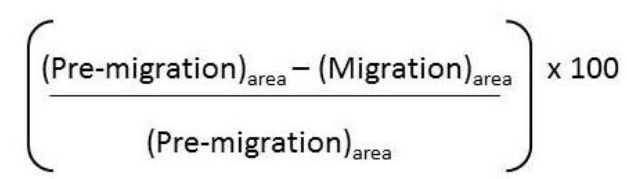

- P 13, L 33: 'to control for any' -> 'to control any'

The requested change has been made.

- P 15, Sub-title 3.3 and in subsequent occurrences: Ser116 numbering should not be a superscript.

All Ser ${ }^{116}$ have been changed to Ser116.

- P 15, L 6: Please remove duplicated 'to be'

The duplicated "to be" has been removed.

- P 16, L 37: I suspect a word needs to be inserted after 'PEA15'. The oncogenic role is not simply its existence but rather its over-activity. Suggest adding the word 'over-expression'.

This now reads "confirming an oncogenic role for PEA-15 over-expression in both oestrogen receptor-positive and TNBC cell lines"

- $\quad P$ 16, $L$ 39: The definition of TNBC should have been made upon first usage on $P$ 12, L 54 .

TNBC is now defined on P12, L54.

- P 16, L 55: 'MCF-7' -> 'MCF7' like all the other occurrences in the manuscript.

All instances of MCF-7 in the text have been changed to MCF7. 
- P 17, L 10 \& 12: The same figure/subfigure is referred to in two different contexts. Please amend.

This has been amended and now reads: "Over-expression of PP4c in (-)siRNA transfected cells decreased the number of viable cells by more than $40 \%$ and enhanced the level of basal apoptosis but had no effect on the number of viable cells and the level of apoptosis in cells which had been previously transfected with PEA-15 siRNA (Figure 9C,D).

- P 18: The first few lines appear to be very much a repetition of the last 4 lines on $P 16$

We have changed these lines. This now reads: "Increased in PP4c protein levels in both oestrogen receptor-positive and TNBC cells was associated with the consistent and significant decrease in both short and long term viability and stimulated apoptosis in the absence of extracellular stimuli."

- P 18, L 28: 'PP4c' here is superfluous. Please confirm / remove.

The unnecessary PP4c has been removed.

- P 18, L 45: The sentence starting 'PP4c also plays a role' feels like a repetition.

The sentence has been removed.

- P 19, L 13: Please define what 'sensitizes' means. Does it make cells more sensitive or less sensitive to cisplatin?

This now reads: "inhibition of PP4c expression increased the sensitivity of breast and lung cancer cells to cisplatin treatment"

- P 19, L 28: 'embryonic kidney human cells' -> 'human embryonic kidney cells'

The change has been made.

- P 20, L 52-60: Very long sentence, with intervening phrases that complicate the context. Suggest writing it as: 'Over-expression of PP4c (which correlated with increased apoptosis and reduced proliferation), caused a significant decrease in the phosphorylation level pf PEA15. Conversely, down-regulation of PP4c (which stimulated proliferation and inhibited apoptosis), resulted in ...'

This now reads: "Over-expression of PP4c (which correlated with increased apoptosis and reduced proliferation), caused a significant decrease in the phosphorylation level pf PEA15. Conversely, down-regulation of PP4c (which stimulated proliferation and inhibited apoptosis) prevented the de-phosphorylation of PEA15, leading to an increase in the content of its phosphorylated form at Ser116."

- P 22, L 17: The closing sentence ' These findings ...' is a repetition of a statement on the previous page. The authors need tom decide whether this is the correct place for this statement, or whether to down-play it in previous text. 
The statement in P21, L52-57 has been removed and placed on P 22, L 17, before the closing statement.

Comments on 'Discussion'

In response to the reviewer's comments we have made the following changes to the discussion:

- The interpretation of the results on $P 19$, starting on $L 5$, is a typical text for covering all bases. The authors true opinion is not coming through forcefully, as I think it ought to. This is a significant result and there should be strong direction from the authors as to what it means. It feels weak.

To address the reviewer's comments, we have inserted into the paragraph the following statement: "Our study reveals that PP4c endogenous level is of critical importance for the survival and growth of breast cancer cells".

We have also removed potential from the sentence : "point to a potential tumour suppressor function for this protein in breast cancer."

The paragraph now reads:

"Our study reveals that PP4c endogenous level is of critical importance for the survival and growth of breast cancer cells. Modulation of the expression of the catalytic subunit of PP4 was shown to cause significant and specific effects on the survival and proliferation of breast cancer cells. Increased in PP4c protein levels in both oestrogen receptor-positive and TNBC cells was associated with the consistent and significant decrease in both short and long term viability and stimulated apoptosis in the absence of extracellular stimuli. We have also shown that PP4c knockdown caused an increase in the rate of cell proliferation and migration in both cell types. Together, the data support an important role for PP4c in maintaining the delicate balance between cell survival and cell death in a range of breast cancer cell types and point to a tumour suppressor function for this protein in breast cancer."

- "The statement at the bottom of P 20 'Conversely, down-regulation of PP4c ... resulted in significant elevation ... of phosphorylated Ser116'. This last statement is not accurate. The increased phosphorylation is the result of depleted PP4c, but not caused by it."

Instead of " down-regulation of PP4c .... resulted in significant elevation of phosphorylated Ser116'. We have changed the sentence to "down-regulation of ------- prevented the de-phosphorylation of PEA15, leading to an increase in the content of phosphorylated Ser116".

- The comment above is directly linked to the statement on P 21, L 30. PEA15 is not being switched from tumour suppressor to promoter. I think it is better described as a growth factor that needs to be carefully controlled, hence the existence of PP4c.

We appreciate the comments relating to the tumour suppressor/ promotor activity of PEA-15. However, PEA15 has been described in the literature to display tumour suppressor or promoter activity dependent on its phosphorylation state (Please refer to Sulzmaier et al., 2012. 
Phosphorylation is the switch that turns PEA-15 from tumour suppressor to tumour promoter. Small GTPases. 2012; 3(3): 173-177). Therefore, we believe that it is justified to use this phrasing in relation to our work on the regulation of PEA15 activity by PP4. 
Highlights

- PP4c over-expression enhances apoptosis and decreases the short and long term survival of breast cancer cells.

- Down-regulation of PP4c increases cell survival, migration and attenuates basal apoptosis in breast cancer cells.

- PP4c regulates the phosphorylation of PEA15, and PEA15 itself regulates the survival of breast cancer cells.

- The inhibitory effects of PP4c on cell survival are mediated through de-phosphorylation of PEA15.

- The PP4-PEA15 signalling axis regulates the survival of breast cancer cells. 


\section{Background}

The control of breast cell survival is of critical importance for preventing breast cancer initiation and progression. The activity of many proteins which regulate cell survival is controlled by reversible phosphorylation, so that the relevant kinases and phosphatases play crucial roles in determining cell fate. Several protein kinases act as oncoproteins in breast cancer and changes in their activities contribute to the process of transformation. Through counteracting the activity of oncogenic kinases, the protein phosphatases are also likely to be important players in breast cancer development, but this class of molecules is relatively poorly understood. Here we have investigated the role of the serine/ threonine protein phosphatase 4 in the control of cell survival of breast cancer cells.

\section{Methods}

The breast cancer cell lines, MCF7 and MDA-MB-231, were transfected with expression vectors encoding the catalytic subunit of protein phosphatase 4 (PP4c) or with PP4c siRNAs. Culture viability, apoptosis, cell migration and cell cycle were assessed. The involvement of phosphoprotein enriched in astrocytes 15 kD (PEA15) in PP4c action was investigated by immunoblotting approaches and by siRNAmediated silencing of PEA15.

\section{Results}

In this study we showed that PP4c over-expression inhibited cell proliferation, enhanced spontaneous apoptosis and decreased the migratory and colony forming abilities of breast cancer cells. Moreover, PP4c down-regulation produced complementary effects. PP4c is demonstrated to regulate the phosphorylation of 
PEA15, and PEA15 itself regulates the apoptosis of breast cancer cells. The inhibitory effects of PP4c on breast cancer cell survival and growth were lost in PEA15 knockdown cells, confirming that PP4c action is mediated, at least in part, through the de-phosphorylation of apoptosis regulator PEA15.

\section{Conclusion}

Our work shows that PP4 regulates breast cancer cell survival and identifies a novel PP4c-PEA15 signalling axis in the control of breast cancer cell survival. The dysfunction of this axis may be important in the development and progression of breast cancer. 
The protein phosphatase 4 - PEA15 axis regulates the survival of breast cancer cells

Hiba N Mohammed ${ }^{1}$, Mark R Pickard ${ }^{2}$, Mirna Mourtada-Maarabouni ${ }^{1 *}$

${ }^{1}$ School of Life Sciences, Faculty of Natural Sciences, Keele University, Keele, Staffs, ST5 5BG, United Kingdom. ${ }^{2}$ Institute of Medicine, University of Chester, Chester CH2 1BR, United Kingdom.

E-mails addresses: h.n.mohammed@keele.ac.uk (Hiba N Mohammed);

m.pickard@chester.ac.uk (Mark R Pickard)

*Corresponding author M.Mourtada-Maarabouni is to be contacted at Tel: +44 1782 733679; fax: +44 1782 583516; e-mail: m.m.maarabouni@keele.ac.uk. 


\section{Abstract}

\section{Background}

The control of breast cell survival is of critical importance for preventing breast cancer initiation and progression. The activity of many proteins which regulate cell survival is controlled by reversible phosphorylation, so that the relevant kinases and phosphatases play crucial roles in determining cell fate. Several protein kinases act as oncoproteins in breast cancer and changes in their activities contribute to the process of transformation. Through counteracting the activity of oncogenic kinases, the protein phosphatases are also likely to be important players in breast cancer development, but this class of molecules is relatively poorly understood. Here we have investigated the role of the serine/ threonine protein phosphatase 4 in the control of cell survival of breast cancer cells.

\section{Methods}

The breast cancer cell lines, MCF7 and MDA-MB-231, were transfected with expression vectors encoding the catalytic subunit of protein phosphatase 4 (PP4c) or with PP4c siRNAs. Culture viability, apoptosis, cell migration and cell cycle were assessed. The involvement of phosphoprotein enriched in astrocytes $15 \mathrm{kD}$ (PEA15) in PP4c action was investigated by immunoblotting approaches and by siRNAmediated silencing of PEA15.

\section{Results}

In this study we showed that PP4c over-expression inhibited cell proliferation, enhanced spontaneous apoptosis and decreased the migratory and colony forming abilities of breast cancer cells. Moreover, PP4c down-regulation produced complementary effects. PP4c is demonstrated to regulate the phosphorylation of 
PEA15, and PEA15 itself regulates the apoptosis of breast cancer cells. The inhibitory effects of PP4c on breast cancer cell survival and growth were lost in PEA15 knockdown cells, confirming that PP4c action is mediated, at least in part, through the de-phosphorylation of apoptosis regulator PEA15.

\section{Conclusion}

Our work shows that PP4 regulates breast cancer cell survival and identifies a novel PP4c-PEA15 signalling axis in the control of breast cancer cell survival. The dysfunction of this axis may be important in the development and progression of breast cancer.

\section{Keywords}

PP4; PP4c; Breast cancer; PEA15, Cell survival. 


\section{Introduction}

Breast cancer is a highly complex and heterogeneous disease, and can be classified into different molecular subtypes according to the expression status of oestrogen receptor $(E R)$, progesterone receptor $(\mathrm{PR})$, and human epidermal growth factor receptors (HERs), HER2/Neu and HER1/EGFR [1,2]. Phosphorylation of these receptors on tyrosine (Tyr) residues constitutes a major regulatory mechanism of their activities. Aberrant activation of these receptors dysregulates multiple signalling cascades and plays a vital role in the initiation, development and progression of breast cancer, highlighting the importance of protein phosphorylation in the context of breast oncogenesis [3]. While the protein tyrosine kinase (PTK) families comprising the HERs and the non-receptor Src-family kinases (SFKs) have been directly implicated in the development and progression of breast cancer [3], their downstream signalling is mainly mediated via the activation of effector pathways that involve serine/threonine (Ser/Thr) kinases, including MAP kinase (MAPK), the phosphoinositide-3 kinase (PI3K)/Akt/mammalian target of rapamycin (mTOR) and the JAK/STAT signalling pathways [4]. The role of Ser/Thr kinases in breast cancer as crucial effectors in oncogenic PTK signalling has been well studied and multiple compounds that target their activity are being evaluated in clinical trials [5].

In contrast, the role of protein phosphatases, the enzymes that reverse the action of protein kinases, is relatively under-studied. This is despite the tumour suppressor function of protein phosphatase 2A (PP2A), a major serine/threonine phosphatase, having been clearly demonstrated in breast, gastric and ovarian cancer cells [6]. Notably, the Ser/Thr phosphatase family contains a number of other subfamilies (i.e. PP1, PP4, PP5, PP6 and PP7), the tumour suppressive functions of which remain to be explored in detail in breast cells [7]. Nevertheless, evidence is emerging from 
other cell types to indicate a crucial role for the PP4 subfamily in the control of cell survival, in particular [7]. PP4 (Protein phosphatase 4; PPP4; PPX) exists as a holoenzyme composed of a highly conserved catalytic subunit (PP4c) which interacts with different structural and regulatory subunits which control its activity, as well as its subcellular localisation [7]. A vast array of regulatory subunits have been described, including alpha 4/ immunoglobulin (CD79A) binding protein 1 ( $\alpha 4$ / IGBP1) which is the only subunit shared with PP2A [8-13].

Like PP2A, PP4 complexes are involved in multiple fundamental cellular processes, including nucleation, organelle assembly, regulation of microtubule growth, growth and maturation of the centrosome during cell division, cell migration, as well as spliceosomal assembly via interaction with the SMN complex $[14,9]$. At the molecular level, PP4 controls haematopoietic progenitor kinase 1 (HPK1), NFKB and histone deacetylase activities [15-17] and regulates JNK and the target of rapamycin (TOR) signalling pathways [18]. PP4 also regulates the dephosphorylation of H2AX, the replication protein A (RPA) $[19,20]$ and KRAB-domain-associated protein 1 (KAP-1) implicating it in regulation of the DNA damage response [21].

Accumulating evidence has demonstrated that the catalytic subunit of PP4 (PP4c) plays important and complex roles in apoptosis and cell proliferation and consequently, in cancer. Over-expression of PP4c increases cell death and decreases cell proliferation in mouse thymoma cells [22], in the human embryonic kidney cell line HEK 293T [22], and in both leukemic T-cells and untransformed human peripheral T-cells [23]. In the latter cells, down-regulation of PP4c causes an increase in the rate of cell proliferation and confers resistance to a number of apoptotic stimuli [23]. On the other hand, a reduction in endogenous PP4c increases 
the basal apoptotic rate of A549 and HeLa cells [24]. Such cell-specific effects of PP4c on cell survival could be related to the differential expression of the various regulatory subunits, resulting in the formation of PP4 complexes with distinct subcellular locations and molecular targets. Overall, these observations suggest that PP4c dysfunction may be important in the development and progression of cancer. The additional observation that PP4c expression is elevated in breast cancer $[25,26]$, further highlights the need for further studies to characterise its role in breast cells.

Proteomic analysis has shown that changes in PP4c expression in human embryonic kidney 293T cells affects the phosphorylation status of many proteins involved in apoptosis and cell proliferation, including the critical apoptosis regulator, phosphoprotein enriched in astrocytes $15 \mathrm{kD}$ (PEA15) [27]. Further analysis has confirmed the interaction between PP4c and PEA15 and demonstrates that PP4c induced apoptosis in normal lymphocytes and T-leukemic cells is partly mediated through the direct or indirect dephosphorylation of PEA15 [23]. PEA15 is a member of the death effector domain (DED) protein family known to regulate cell proliferation, autophagy, and apoptosis $[28,29]$. It is implicated in the dysregulation of many signalling pathways involved in cancer progression and tumorigenesis and it has been described to act as both a tumour suppressor and a tumour promoter, dependent on its phosphorylation status [30-32]. The PEA15 gene is amplified in breast cancer, as well as in other cancers [33], and the unphosphorylated form of PEA15 is more potent than the phosphorylated form in suppressing tumorigenicity in breast cancer [34]. While several kinases have been reported to be involved in the phosphorylation of PEA15 including Akt, Ca2+/calmodulin-dependent protein kinase (CaMKII) and AMP-activated protein kinase (AMPK) $[35,36]$, the dephosphorylation of PEA15 is much less understood. 
In this study, we have investigated the role of PP4c in the control of survival of hormone-sensitive and triple-negative breast cancer cells. Firstly, we have investigated the hypothesis that PP4c regulates the survival and proliferation of breast cancer cells. Secondly, we have explored the interaction between PP4c and PEA15 and have specifically addressed the involvement of PEA15 in mediating the functional responses of breast cancer cells to PP4c. Together, these studies reveal the importance of PP4c expression levels in the control of survival of breast cancer cells and provide support for a tumour suppressor role for PP4c. Our findings also indicate that the critical role played by PP4c in maintaining the delicate balance between cell survival and cell death in breast cancer cells is mediated, at least partly, through the dephosphorylation of PEA15.

\section{Materials and methods}

2. 1 . Cell culture

The breast cancer cell lines MCF7 [37] and MDA-MB-231 [38] were generated from secondary stocks of cells which had been frozen down within two weeks of receipt from ATCC-LGC Promochem (Teddington, Middlesex, UK). Cells were cultured in R10 medium (RPMI-1640; Sigma Aldrich Company Ltd) supplemented with 2 mM Lglutamine, $1 \mathrm{mM}$ sodium pyruvate, $10 \mathrm{mM}$ HEPES, 10\% fetal bovine serum and 50 $\mu \mathrm{g} / \mathrm{ml}$ gentamicin at $37{ }^{\circ} \mathrm{C}$ in a humidified incubator with $5 \% \mathrm{CO}_{2}$. Cell lines were replaced with freshly thawed stocks every 6 - 8 weeks. All experiments were carried out using cells in logarithmic growth phase. 


\section{2. Plasmid DNA transfection}

Plasmids were pcDNA3.1-PP4c [23,27], and empty pcDNA3.1 vector as control. MCF7 breast cancer cells were transfected using TransIT-BrCa tranfection reagent (Mirus Bio LLC, Madison, USA) according to the manufacturer's instructions at a DNA: reagent ratio of 1:2. MDA-MB-231 cells were nucleofected $(2 \mu \mathrm{g}$ plasmid per 2 x $10^{6}$ cells in $0.1 \mathrm{ml}$ Ingenio solution (Mirus Bio LLC, Madison, USA)) using programme X-013. Following nucleofection, cells were plated in $3 \mathrm{ml} \mathrm{R-10} \mathrm{medium} \mathrm{in}$ 6-well plates. Efficiency of transfection was $70-80 \%$ for MCF7 and $80-85 \%$ for MDAMB-231.The level of expression of PP4c was monitored by western analysis [22,23].

\section{3. RNA interference}

MCF7 and MDA-MB-231 breast cancer cells were transfected with siRNAs to PP4c, using RNAiFect reagent (Qiagen, Crawley, UK) according to a standard protocol [39]. Three different PP4c specific siRNAs were employed, termed PP4s1 (targets exon 7; product code n105835), PP4s2 (targets exon 4; product code n105834) and PP4s8 (targets exon 6, product code SI02658698); PP4s1 and PP4s2 were purchased from Life Technologies Ltd (Paisley, UK), whereas PP4s8 was purchased from Qiagen (Crawley, UK). Two different PEA15 specific siRNAs were used, termed PEA15s1 and PEA15s2 (product codes/targeted exons are: n137203/ exon 4 and n43349/exon 2, respectively). Controls were transfected with negative control (()siRNA; code AM4611, Life Technologies Ltd, Paisley, UK). Transfection efficiency (80-90\% at 48 h) was determined in parallel transfections with Cy3-labelled (-)siRNA prepared using the SilencerTM siRNA labelling kit (Ambion; Cat\# 1632). Monitoring of specific silencing of PP4C and PEA15 expression was carried out on samples collected at $72 \mathrm{~h}$ post-transfection by western blotting. 


\subsection{Determination of cell survival and apoptosis}

At $24 \mathrm{~h}$ post-transfection with plasmids or at $72 \mathrm{~h}$ post-transfection with siRNAs, cells were harvested by trypsinization then seeded $\left(0.8 \times 10^{5}\right.$ cells for siRNA-transfected cells; $1.6 \times 10^{5}$ cells for plasmid-transfected cells) into 12-well plates. Cells were cultured for 24 and $48 \mathrm{~h}$ before being trypsinized to determine cell viability and apoptosis. Cell viability was determined by counting of nigrosin blue $(0.1 \%, w / v)$ stained samples using a haemocytometer and light microscopy. Cell viability was also determined using a commercial Cell Count and Viability Kit and a Muse flow cytometer (Merck Millipore, Darmstadt, Germany). Apoptosis was routinely determined by assessment of nuclear morphology by fluorescence microscopy after staining with acridine orange $(25 \mu \mathrm{g} / \mathrm{ml})$; cells containing condensed or fragmented chromatin were scored as apoptotic. Apoptosis was also measured by flow cytometry using a Muse annexin $\mathrm{V}$ and dead cell assay kit, according to the manufacturer's protocol (Merck Millipore, Darmstadt, Germany). For clonogenic assays, cells were replated in culture medium supplemented with $10 \%(\mathrm{v} / \mathrm{v})$ cellconditioned medium in 6-well plates, cultured for 3 weeks, and then the number of colonies was counted after staining with crystal violet. Cell migration was assessed using the scratch wound healing assay. Cells were seeded in 24-well plates at a density of $1.6 \times 10^{4}$ cells/well in complete R-10 medium and cultured to confluence. The confluent cells were serum-starved for 24 hours, then cell monolayers were scratched using a $200 \mu$ pipette tip to generate scratch wounds. Cells were washed twice with Opti-MEM (Invitrogen; \# 51985-026) to remove cell debris and serumcontaining media was added to each well. The initial wound area was measured in four places using a calibrated eyepiece graticule to document the pre-migration area of the cell-free detection zone. The distance across each wound was then measured 
in four places every 18 hour or until wounds were completely closed. Cells were incubated at $37{ }^{\circ} \mathrm{C}, 5 \% \mathrm{CO}_{2}$ at all times. Cell migration is presented as percent wound closure and was calculated using the following equation:

$$
\left(\frac{(\text { Pre-migration })_{\text {area }}-(\text { Migration })_{\text {area }}}{(\text { Pre-migration })_{\text {area }}}\right) \times 100
$$

\section{5. Cell cycle analysis}

Cell cycle analysis was assessed by flow cytometry following nuclear propidium iodide staining using the Muse cell cycle kit (Merck Millipore, Darmstadt, Germany). At $24 \mathrm{~h}$ post-transfection with plasmids or at $72 \mathrm{~h}$ post-transfection with siRNAs, cells were harvested by trypsinization and were plated in fresh medium at $5 \times 10^{5}$ cells/well in $4 \mathrm{ml}$ medium in 6-well plates. Following incubation for $24 \mathrm{~h}$, cells $\left(\sim 10^{6}\right)$ were suspended in $200 \mu \mathrm{l}$ phosphate buffered saline (PBS), and fixed in $1 \mathrm{ml}$ icecold $70 \%$ ethanol $/ 30 \%$ PBS. Cells were incubated at $-20{ }^{\circ} \mathrm{C}$ for at least three hours. Cells were then re-suspended in $200 \mu$ l of Muse ${ }^{\mathrm{TM}}$ Cell Cycle Reagent and incubated for 30 minutes in the dark before data was acquired using the Muse Cell analyser.

\section{6. Western blot analysis}

Cells $\left(10^{6}\right)$ were washed twice in PBS and lysed in $50 \mu$ lysis buffer $(50 \mathrm{mM}$ Tris$\mathrm{HCl}, \mathrm{pH}$ 7.5; $150 \mathrm{mM} \mathrm{NaCl}, 1 \%$ Nonidet P40, 1 mM EDTA, $1 \mu \mathrm{M}$ Pepstatin, $10 \mu \mathrm{g} / \mathrm{ml}$ Leupeptin, $1 \mathrm{mM}$ PM Phenylmethanesulfonyl fluoride (PMSF)) on ice for $30 \mathrm{~min}$. Samples were then centrifuged $(10,000 \mathrm{~g}, 10 \mathrm{~min})$ to remove debris. The protein content of the supernatant was quantified using the Coomassie Plus ${ }^{\mathrm{TM}}$ protein assay reagent (PIERCE; Waltham, MA, USA). Protein samples $(50 \mu \mathrm{g})$ were boiled for 10 
min in sample buffer (10\% glycerol, 0.7M $\beta$-mercaptoethanol, 3\% SDS, $62 \mathrm{mM}$ Tris$\mathrm{HCl}, \quad \mathrm{pH}$ 6.8), electrophoresed (12\% SDS-polyacrylamide gels), then electrotransferred onto a polyvinylidenedifluoride membrane (Biorad, Hertfordshire, UK). The blots were probed with either anti-PP4c antibody (PPX/PP4 (C-18); 1:1000 dilution; Santa Cruz Biotechnology, Heidelberg, Germany \# Sc6118), anti-PEA15 antibody (1:1000 dilution, Santa Cruz \# Sc28255), or phosphospecific anti-PEA15 specific for Ser116 (P-PEA15, dilution 1:500; \# 44-836G; Biosource) followed by the appropriate horseradish peroxidase-conjugated secondary antibodies. Blots were stripped using Restore(TM) Plus Western Blot Stripping Buffer Kit (Pierce; \# 10016433) and reprobed with anti- $\beta$-actin antibody (dilution 1:5000; Sigma, \# A5441). The secondary antibodies used were anti-goat IgG (diluted 1:10.000; Sigma, \# A5420), anti-mouse immunoglobulin (diluted 1:800; Dako, \# P0447) and anti-rabbit IgG (diluted 1:10000; Sigma, \# A0545). Protein bands were visualised by enhanced chemiluminescence (ECL) according to the manufacturer's instructions (Amersham Pharmacia Biotech, ,Little Chalfont, Buckinghamshire, UK) signals were captured utilizing the Odyssey® Imager (Li-Cor, Lincoln, Nebraska USA) and densitometric analysis carried out using the associated Image Pro analysis software (version 3.1).

\section{7. Statistical analyses}

Data are presented as the mean \pm SEM; the number of observations $(n)$ refers to different transfected samples (each from separate cultures) or separate cultures. Data analysis was either by an unpaired Student's $t$ test or by one-way analysis of variance with Bonferroni's multiple comparison test (MCT). Statistical analyses were performed using GraphPad Prism 6; a p-value of $<0.05$ was considered statistically significant. 


\section{Results}

3.1. Transient expression of PP4c enhances apoptosis and decreases the survival of breast cancer cells

To examine the effects of increased PP4c expression on breast cancer cell survival, MCF7 cells were transiently transfected with a pcDNA3.1 expression plasmid containing full length cDNA encoding PP4c. The influence of PP4c over-expression on cell survival and apoptosis was then examined under basal conditions. Transient transfection resulted in an approximate doubling in PP4c protein level at $24 \mathrm{~h}$ post transfection (Fig. 1A). This had significant effects on cell survival and basal apoptosis. Compared to cultures of untransfected cells and cells transfected with empty vector, the number of both total and viable cells in cultures over-expressing PP4c was considerably decreased at $48 \mathrm{~h}$, as assessed by vital dye staining and flow cytometry (Fig. 1B and S1A). Cells over-expressing PP4C also showed a 15$20 \%$ increase in apoptotic cells (Fig. 1C and S1B). In order to determine whether the growth suppression produced by PP4c was due to apoptosis, to cell cycle arrest, or to both, a cell cycle analysis was performed using propidium iodide staining and flow cytometry. The results revealed a significant increase in the proportion of cells in the sub-G0 phase in PP4c over-expressing cultures, suggesting an increase in the apoptosis rate, and a consistently lower percentage of cells in G1 and S phases (Fig. 1D). In the longer term, these various effects resulted in a significant decrease in the clonogenic activity of MCF7 cells (Fig. 1E).

To confirm these findings, the triple-negative breast cancer (TNBC) cell line, MDAMB-231, was transfected with the plasmid encoding PP4c. This also produced an approximate doubling of cellular PP4c protein levels (Fig. 2A) and caused a 
significant reduction in total and viable cell number (Fig. 2B and S2A). This was also associated with a doubling of basal apoptosis (Fig. 2C and S2B). Cell cycle analysis confirmed an increase in the proportion of cells in the sub-G0 fraction after transfection with pcDNA3.1-PP4c, whereas the proportions of cells in G1, S and G2/M phases were decreased (Fig. 2D). Over-expression of PP4c in MDA-MB-231 also caused a significant reduction in the clonogenic activity of these cells (Fig. 2E). Thus, PP4c causes growth arrest, induces apoptosis and decreases long term survival in both triple-negative MDA-MB-231 cells and oestrogen receptor-positive MCF7 cells.

3. 2. PP4c silencing increases cell survival, migration and attenuates basal apoptosis in breast cancer cells

In order to investigate PP4c function further in MCF7 and MDA-MB-231 cells, siRNAmediated silencing of PP4c expression was conducted using two different PP4cspecific siRNAs per cell line, which target different exons, in order to control any 'offtarget' effects. This complementary strategy of independent over-expression and gene silencing approaches is particularly important to exclude possible artefacts. The efficiency of PP4c knockdown was determined by immunoblotting $72 \mathrm{~h}$ posttransfection and the influence of PP4c silencing on long-and short-term cell survival and apoptosis was again examined under basal conditions.

In MCF7 cells, the two PP4c-targeted siRNAs each reduced PP4c protein levels by $70-80 \%$ (Fig. 3A). Both siRNAs increased the numbers of total and viable cells (Fig. 3B and S3A) and decreased the level of basal apoptosis (Fig. 3C and S3B). Cell cycle analysis revealed that PP4c silencing decreased the proportion of cells in subG0 and increased the proportions of cells in $S$ and G2/M phases (Fig. 3D). The 
clonogenic activity of MCF7 cells was also increased in the cells transfected with PP4c specific siRNAs (Fig. 3E).

siRNA-mediated silencing of PP4c expression in MDA-MB-231 produced an 80 85\% decrease in endogenous PP4c protein levels (Fig. 4A). As in MCF7 cells, this was associated with an increase in the number of total and viable cells (Fig. 4B and S4A) and a decrease in spontaneous apoptosis (Fig. 4C and S4B). Cell cycle analysis confirmed that PP4c silencing produced a substantial reduction in the proportion of cells in the sub-G0 fraction (Fig. 4D). The proportion of cells in G1 was also consistently lower compared to the negative control siRNA, whereas the proportion of cells in S and G2/M phases was consistently higher, suggesting that PP4c down-regulation may accelerate G1 progression (Fig. 4D). PP4c silencing also significantly increased the long term survival of MDA-MB-231, as shown by an increase in the number of colonies formed (Fig. 4E).

The effect of PP4c silencing on cell migration was also assessed using an in-vitro scratch assay. RNA mediated silencing of PP4c promoted cell migration in both MCF7 and MDA-MB-231 cells. As shown in Fig. 5A, down-regulation of PP4c was found to increase MCF7 cell migration by up to $30 \%$ at 36,54 and $72 \mathrm{~h}$ compared with (-)siRNA and mock transfected cells. Consistent with these observations, PP4c knockdown in MDA-MB-231 cells showed a significant increase in cell migration ability by $30 \%$ at $18 \mathrm{~h}$ and by $20 \%$ at 36 and $54 \mathrm{~h}$ (Fig. 5B). Overall, the data indicate that PP4c down-regulation enhances breast cancer cell proliferation and migration, with implications for breast cancer progression and metastasis. 
3. 3. PP4c down-regulation leads to an increase in the PEA15 Ser116 phosphorylation

PEA15 is one of the proteins reported to be regulated, directly or indirectly, through dephosphorylation by PP4c $[30,35]$. Previous studies have shown that overexpression of PP4c correlates with dephosphorylation of PEA15 on Ser116, while PP4c silencing results in an increase in the level of phosphorylated Ser116 [23,27]. In order to investigate whether PP4c regulates the phosphorylation level of PEA15 in breast cancer cells, the status of PEA15 phosphorylation was measured in the cells transfected with PP4c siRNAs and pcDNA3.1-PP4c using an antibody that specifically recognises the phosphorylated form of PEA15 on Ser116. Western blot analysis on proteins extracted from MCF7 and MDA-MB-231 PP4c knockdown cells revealed that PEA15 phosphorylation state significantly increased when PP4C expression was suppressed. PP4c down-regulation caused up to 1.5 - 2-fold increase in the phosphorylated form of PEA15 on Ser116 in MCF7 (Fig. 6A) and in MDA-MB-231 cells (Fig. 6B). Western blot analysis on proteins extracted from MCF7 cells over-expressing PP4c revealed that over-expression of PP4c caused a corresponding decrease in the phosphorylation state of PEA15 (Fig. 6C), providing further evidence to support the involvement of PP4c in regulating the phosphorylation status of PEA15.

3. 4. The effects of PP4c on cell survival and apoptosis are mediated at least partly by PEA15 
The control of apoptosis and cell proliferation by PP4c in leukemic and primary human T-cells was demonstrated to be mediated at least partly through the dephosphylation of PEA15 on Ser116 [23,27]. Further experiments were carried out in order to investigate whether PEA15 plays a major role in mediating the proapoptotic and growth inhibitory effects of PP4c in breast cancer cells. Two PEA15specific siRNAs were used to down-regulate PEA15 before studying the effects of modulation of PP4c expression on cell viability. Down-regulation of PEA15 in MCF7 cells was assessed at $48 \mathrm{~h}$ post-transfection which showed that both PEA15 siRNAs were effective in causing a decrease in PEA15 protein levels by $60-75 \%$ (Fig. 7A). In agreement with a previous study [36], down-regulation of PEA15 resulted in significant decreases in the number of viable cells (Fig. 7B) and cell viability (Fig. 7C), and a significant increase in basal apoptosis (Fig. 7D). Consistent with these observations, silencing of PEA15 gene expression in MDA-MB-231 cells also resulted in a decrease in PEA15 protein levels (Fig. 8A) and this was accompanied by reductions in the viable cell number (Fig. 8B) and cell viability (Fig. 8C), and an increase in basal apoptosis (Fig. 8D), confirming an oncogenic role for PEA15 overexpression in both oestrogen receptor-positive and TNBC cell lines.

To investigate a potential role for PEA15 in PP4c action, control cells (transfected with (-) siRNA) and cells transfected with PEA15 siRNAs were transiently transfected with pcDNA3.1-PP4c or pcDNA3.1 (transfection efficiency 70 - 80\%). Overexpression of PP4c was assessed by western blotting which showed a two-fold increase in the level of PP4c in the cells transfected with PP4c expression vector (data not shown). In MCF7 cells transfected with (-) siRNA, over-expression of PP4C caused the expected reduction in viable cell number (Fig. 9A) and the expected increase in basal apoptosis (Fig. 9B). In contrast, over-expression of PP4c in cells 
which had been previously transfected with PEA15 siRNA had no effects on the viable cell number and apoptosis level (Fig. 9A, B). These findings were confirmed in the TNBC MDA-MB-231 cells. Over-expression of PP4c in (-)siRNA transfected cells decreased the number of viable cells by more than $40 \%$ and enhanced the level of basal apoptosis but had no effect on the number of viable cells and the level of apoptosis (Fig. 9C,D).

\section{Discussion}

Reversible protein phosphorylation, controlled by the opposing action of protein kinases and phosphatases, regulates many cellular processes. Disturbance to the well balanced function of kinases and phosphatases contributes to the development and progression of various cancers including breast cancer [5]. Many kinases are now characterised to be oncogenic and changes in their activities have been linked to the pathogenesis and progression of breast cancer. However, the roles played by the phosphatases are much less clear and less well studied, although logically, they must be important through their ability to counteract the activities of the kinases [5]. Indeed, phosphatases such as PP2A [41,42], phosphatase and tensin homologue deleted on chromosome 10 (PTEN) and Src homology 2 (SH2)-containing inositol 5phosphatase (SHIP) are recognised as potential therapeutic targets due to their tumour suppressor activities $[43,23]$. Here we demonstrate, for the first time, that the serine/threonine phosphatase PP4 regulates the survival, proliferation and migration of oestrogen receptor-positive and TNBC breast cancer cells. We further demonstrate that these effects are mediated in part by modulation of the phosphorylation state of PEA15, pointing to the existence of a PP4c-PEA15 axis that controls breast cancer cell fate. 
Our study reveals that PP4c endogenous level is of critical importance for the survival and growth of breast cancer cells. Modulation of the expression of the catalytic subunit of PP4 was shown to cause significant and specific effects on the survival and proliferation of breast cancer cells. Increased in PP4c protein levels in both oestrogen receptor-positive and TNBC cells was associated with the consistent and significant decrease in both short and long term viability and stimulated apoptosis in the absence of extracellular stimuli. We have also shown that PP4c knockdown caused an increase in the rate of cell proliferation and migration in both cell types. Together, the data support an important role for PP4c in maintaining the delicate balance between cell survival and cell death in a range of breast cancer cell types and point to a tumour suppressor function for this protein in breast cancer.

Indeed PP4c has been reported to negatively regulate the survival of other cell types, including both leukemic T-cells and untransformed human peripheral blood Tcells [23], in keeping with our findings here. Studies of a wide range of cell types other than breast epithelial cells have revealed that PP4 regulates an increasing number of cellular functions. The pleiotropic effects of PP4c have been related to the existence of different PP4 complexes that have different compositions as a result of the interaction of PP4c with different regulatory subunits $[7,16]$. The enzyme is involved in the regulation of microtubule growth and organization at the centrosomes [9], centrosome maturation in mitosis and meiosis and DNA damage response [8, 44]. Recent evidence suggested that PP4c controls neural progenitor cell proliferation and differentiation in the mouse neocortex by regulating the phosphorylation status of Nuclear distribution protein nudE-like1 (Ndel1) [34]. PP4c interacts with and down-regulates insulin receptor substrate 4 (IRS4) following tumour necrosis factor-alpha (TNF-a) stimulation leading to the inhibition of the anti- 
apoptotic function of IRS4 [45]. Such evidence is entirely consistent with the findings form the present studies and suggest potential downstream mechanisms underlying regulation of cell survival by PP4c in a cell context-dependent manner.

On the other hand, the exact role of PP4c in relation to cancer is not clear, with some studies suggesting a tumour suppressor role, while others support an oncogenic role. For example, PP4c levels are increased in human breast and lung tumours, and inhibition of PP4c expression increased the sensitivity of breast and lung cancer cells to cisplatin treatment, suggestive of an oncogenic function [25]. PP4c is also over-expressed in pancreatic ductal adenocarcinoma (PDAC) and is associated with a poor prognosis [26]. Also PP4c has been reported to be expressed constitutively in prostate cancer cell lines (PC-3 and LNCaP) where it acts as a positive regulator of the MAP kinase JNK-1 [18]. Other studies have however shown that PP4c over-expression in 293T human embryonic kidney cells, T-leukemic cells and primary lymphocytes causes an increase in apoptosis, an inhibition of cell proliferation by inducing cell cycle arrest in G1 and a significant decrease in the mutation rate, and conversely, that decreased PP4c protein expression increases the rate of cell proliferation and protects the cells against apoptosis induction by a range of stimuli [22-27]. These and present findings together support a tumour suppressor role for PP4c. To resolve these conflicting views, further information is required about the functional activity of PP4c in breast and other cancers, especially since this is dependent on the expression of regulatory subunits. For example, the regulatory subunit, PP4R1, is down-regulated in a subset of malignant $T$ lymphocytes derived from patients with a severe form of cutaneous T cell lymphoma, resulting in inactive PP4c. This in turn results in constitutive IKK/NF-kB signalling, suggesting that PP4R1-PP4c complex serves as a negative regulator of IKK activity 
[16]. It is therefore important to elucidate the functional status of the catalytic subunits in breast cancer and further investigate the precise roles of other individual regulatory subunits and their potential functions during transformation. The possibility of the existence of an endogenous inhibitor should also be investigated, since an endogenous inhibitor of the closely related phosphatase PP2A, has been identified in cells undergoing blast crisis in chronic myeloid leukaemia [46].

A key finding in these studies was that PP4c influenced the phosphorylation status of PEA15, especially since PEA15 is itself implicated in the regulation of cell proliferation and apoptosis [27]. Proteomic analysis has shown that changes in PP4 expression levels affect the phosphorylation status of many proteins involved in apoptosis and cell proliferation, including PEA15 [27]. PEA15 is a multi-functional protein that has been implicated in the regulation of major intracellular processes including proliferation and apoptosis, and its function is tightly regulated by its phosphorylation at two serine residues, Ser104 and Ser116 [27]. Both CaMKII and AKT phosphorylate PEA15 at Ser116 [47-49] and, more recently, AMPK was reported to act as an upstream kinase of PEA15 in both normal and cancerous breast epithelial cells [36]. Phosphatases play an equally important role as kinases in regulating the phosphorylation state of PEA15. In this regard, a loss of PTEN function commonly seen in tumour cells is associated with an increased PEA15 phosphorylation at Ser116 and an inhibition of Fas-mediated apoptosis [50]. However, evidence suggests that PTEN does not dephosphorylate PEA15 directly, but it modulates its phosphorylation level by controlling AKT activity [50]. In this study, we show that PP4c also regulates the phosphorylation of PEA15 at Ser116. Over-expression of PP4c (which correlated with increased apoptosis and reduced proliferation), caused a significant decrease in the phosphorylation level of PEA15. 
Conversely, down-regulation of PP4c (which stimulated proliferation and inhibited apoptosis) prevented the de-phosphorylation of PEA15, leading to an increase in the content of its phosphorylated form at Ser116. Consistent with these observations, others have reported that the non-phosphorylated form of PEA15 binds to the extracellular signal-regulated kinase $1 / 2$ (ERK1/2), preventing its nuclear accumulation, leading to the inhibition of cell proliferation $[30,31]$. On the other hand, phosphorylation of PEA15 on Ser116 promotes its binding to Fas-associated death domain protein (FADD) via its DED domain, preventing FADD-mediated activation of caspases and the formation of the death inducing signalling complex (DISC), leading to the inhibition of the extrinsic apoptotic pathway $[30,33,47]$.

Down-regulation of PEA15 expression was found to inhibit cell growth and to reduce viable cell number and viability, confirming an anti-apoptotic role for PEA15 in breast cancer cells. Crucially, PP4c had no effect on apoptosis in cells with prior knockdown of PEA15 expression, suggesting that the induction of apoptosis by PP4c is mainly mediated through PEA15. Consequently, PP4c may be involved in mediating the switch of PEA15 from a tumour promoter to a tumour suppressor. As discussed above, recent studies have shown that AMPK directly phosphorylates PEA15 at Ser116, thereby converting it to a tumour promoter, resulting in increased survival and anchorage-independent growth of normal and breast cancer cells, both in vivo and in vitro [36]. Thus, PP4c which dephosphorylates PEA15, may counteract the effects of AMPK by switching the activity of PEA15 from a tumour promoter to a tumour suppressor. In this regard, the balance in the activities of AMPK and PP4c are likely to be crucial in determining the phosphorylation status of PEA15 and consequently, the development and progression of breast cancer. 
In summary, oncogenic activation of protein kinases is a common feature in breast cancer, and many anticancer drugs that target these enzymes are now available. Protein phosphorylation is also controlled by protein phosphatases which, compared to kinases, are relatively under-studied. Our studies indicate that PP4c plays a critical role in the delicate balance of cell survival and cell death in breast cancer cells and that these effects are mediated mainly through the dephosphorylation of PEA15, switching the activity of this molecule from a tumour- promoter to a tumoursuppressor. Our study also highlights the high potential therapeutic value of targeting PEA15 and its interactions, which may provide a wider window of opportunities to treat breast cancer. These findings suggest that modulating the levels and activities of PP4c and/or PEA15 may prove important novel strategies for the treatment of breast cancer.

\section{Acknowledgements}

$\mathrm{HM}$ is a PhD student funded by the Ministry of Higher Education and Scientific Research, Republic of Iraq.

\section{References}

1. Malhotra GK, Zhao X, Band $\mathrm{H}$, Band $\mathrm{V}$ : Histological, molecular and functional subtypes of breast cancers. Cancer Biol Ther 2010, 10:955-60.

2. Weigelt B, Geyer FC, Reis-Filho JS: Histological types of breast cancer: how special are they? Mol Oncol 2010, 4:192-208.

3. Hynes NE: Tyrosine kinase signalling in breast cancer. Breast Cancer Res 2000, 2:154-157.

4. Knutson PT, Daniel RA, Fan D, Silverstein ATK, Covington RK, Fuqua AWS, Lange AC: Phosphorylated and sumoylation-deficient progesterone receptors drive proliferative gene signatures during breast cancer progression. Breast Cancer Res 2012, 14:R95. 
5. Nunes-Xavier CE, Martín-Pérez J, Elson A, Pulido R: Protein tyrosine phosphatases as novel targets in breast cancer therapy. Biochim Biophys Acta 2013, 1836:211-26.

6. Maeve Kiely M, Kiely PA: PP2A: The wolf in sheep's clothing? Cancers 2015, 7: 648-669.

7. Cohen PT, Philp A, Vazquez-Martin C: Protein phosphatase 4--from obscurity to vital functions. FEBS Lett 2005, 579:3278-3286.

8. Hastie CJ, Carnegie GK, Morrice N, Cohen PT: A novel 50 KDa protein forms complexes with protein phosphatase 4 and is located at centrosomal microtubule organizing centres. Biochem J 2000, 347:845-55.

9. Carnegie GK, Sleeman JE, Morrice N, Hastie CJ, Peggie MW, Philp A, Lamond $\mathrm{Al}$, Cohen PT: Protein phosphatase 4 interact with the survival of motor neurons complex and enhances the temporal localization of snRNPs. $J$ Cell Sci 2003, 116:1905-1913.

10. Gingras AC, Caballero M, Zarske M, Sanchez A, Hazbun TR, Fields S, Sonenberg N, Hafen E, Raught B, Aebersold R: A novel, evolutionarily conserved protein phosphatase complex involved in cisplatin sensitivity. Mol Cell Proteomics 2005, 4:1725-40.

11. Chen GI, Tisayakorn S, Jorgensen C, D'Ambrosio LM, Goudreault M, Gingras AC: PP4R4/KIAA1622 forms a novel stable cytosolic complex with phosphoprotein phosphatase 4. J Biol Chem 2008, 283:29273-84.

12. Murata $\mathrm{K}, \mathrm{Wu} \mathrm{J}$, Brautigan $\mathrm{DL}$ : B cell receptor associated protein a4 displays rapamycin-sensitive binding directly to the catalytic subunit of protein phosphatase 2A. Proc Natl Acad Sci USA 1997, 94:10624-10629.

13. Chen J, Peterson RT, Schreiber SL: Alpha 4 associated with protein phosphatases 2A, 4 and 6. Biochem Biophys Res Commun 1998, 247:827-32.

14. Toyo-oka $Y$, Shimosato D, Murakami K, Takahashi K, Niwa H: Identification and characterization of subpopulations in undifferentiated ES cell culture. Development 2008, 135:909-18.

15. Shui JW, Hu MC, Tan TH: Conditional knockout mice reveal an essential role of protein phosphatase 4 in thymocyte development and pre-T-cell receptor signalling. Mol Cell Biol 2007, 27:79-91.

16. Brechmann M, Mock T, Nickles D, Kiessling M, Weit N, Breuer R, Müller W, Wabnitz G, Frey F, Nicolay JP, Booken N, Samstag Y, Klemke CD, Herling M, Boutros $\mathrm{M}$, Krammer PH, Arnold R: A PP4 holoenzyme balances physiological and oncogenic nuclear factor-kappa $B$ signaling in $T$ lymphocytes. Immunity 2012, 37:697-708. 
17.Zhang X, Ozawa Y, Lee H, Wen YD, Tan TH, Wadzinski BE, Seto E: Histone deacetylase 3 (HDAC3) activity is regulated by interaction with protein serine/threonine phosphatase4. Genes Dev 2005, 19:827-39.

18. Inostroza J, Sáenz L, Calaf G, Cabello G, Parra E: Role of the phosphatase PP4 in the activation of JNK-1 in prostate carcinoma cell lines PC-3 and LNCaP resulting in increased AP-1 and EGR-1 activity. Biol Res 2005, 38:163-178.

19. Lee DH, Pan Y, Kanner S, Sung P, Borowiec JA, Chowdhury D: A PP4 phosphatasec complex dephosphorylates RPA2 to facilitate DNA repair via homologous recombination. Nat Struct Mol Biol 2010, 17:365-72.

20. Lee J, Adelmant G, Marto JA, Lee DH: Dephosphorylation of DBC1 by Protein Phosphatase 4 Is Important for p53-Mediated Cellular Functions. Mol Cells 2015, 38:697-704.

21. Lee DH, Goodarzi AA, Adelmant GO, Pan Y, Jeggo PA, Marto JA, Chowdhury D: Phosphoproteomic analysis reveals that PP4 dephosphorylates KAP-1 impacting the DNA damage response. EMBO J 2012, 31:2403-15.

22. Mourtada-Maarabouni M, Kirkham L, Jenkins B, Rayner J, Gonda TJ, Starr R, Trayner I, Farzaneh F, Williams GT: Functional expression cloning reveals pro-apoptotic role for protein phosphatase 4. Cell Death Differ 2003, 10:1016-24.

23. Mourtada-Maarabouni M, Williams GT: Protein phosphatase 4 regulates apoptosis in leukemic and primary human T-cells. Leuk Res 2009, 33:153951.

24. Theobald B, Bonness K, Musiyenko A, Andrews JF, Urban G, Huang X, Dean NM, Honkanen R: Suppression of ser/thr phosphatase 4 (PP4C/PPP4C) mimics a novel post-mitotic action of fostriecin, producing mitotic slippage followed by tetraploid cell death. Mol Cancer Res 2013, 11:845855.

25. Wang B, Zhao A, Sun L, Zhong X, Zhong J, Wang H, Cai M, Li J, Xu Y, Liao J, Sang J, Chowdhury D, Pfeifer GP, Yen Y, Xu X: Protein phosphatase PP4 is overexpressed in human breast and lung tumours. Cell Res 2008, 18: 9747.

26. Weng S, Wang H, Chen W, Katz MH, Chatterjee D, Lee JE, Pisters PW, Gomez $\mathrm{HF}$, Abbruzzese JL, Fleming JB, Wang $\mathrm{H}$ : Overexpression of protein phosphatase 4 correlates with poor prognosis in patients with stage II pancreatic ductal adenocarcinoma. Cancer Epidemiol Biomarkers Prev 2012, 21:1336-43. 
27. Mourtada-Maarabouni M, Williams GT: Protein phosphatase 4 regulates apoptosis, proliferation and mutation rate of human cells. Biochim Biophys Acta 2008, 1783:1490-502.

28. Dontu G, Abdallah WM, Foley JM, Jackson KW, Clarke MF, Kawamura MJ, Wicha MS: In vitro propagation and transcriptional profiling of human mammary stem/progenitor cells. Genes Dev 2003, 17:1253-1270.

29. Kim YN, Koo KH, Sung JY, Yun UJ, Kim H: Anoikis resistance: an essential prerequisite for tumor metastasis. Int J Cell Biol 2012, 2012:306879.

30. Glading A, Koziol JA, Krueger J, Ginsberg MH: PEA-15 inhibits tumor cell invasion by binding to extracellular signal-regulated kinase 1/2. Cancer Res 2007, 67:1536-1544.

31. Bartholomeusz C, Rosen D, Wei C, Kazansky A, Yamasaki F, Takahashi T, Itamochi $\mathrm{H}$, Kondo $\mathrm{S}$, Liu J, Ueno NT: PEA-15 induces autophagy in human ovarian cancer cells and is associated with prolonged overall survival. Cancer Res 2008, 15:68:9302-10.

32. Gawecka JE, Geerts D, Koster J, Caliva MJ, Sulzmaier FJ, Opoku-Ansah J, Wada RK, Bachmann AS, Ramos JW: PEA15 impairs cell migration and correlates with clinical features predicting good prognosis in neuroblastoma. Int J Cancer 2012, 131:1556-68.

33. WeiY: On the Quest of Cellular Functions of PEA-15 and the Therapeutic Opportunities. Pharmaceuticals (Basel) 2015, 8:455-73.

34. Xie X, Tang H, Liu P, Kong Y, Wu M, Xiao X, Yang L, Gao J, Wei W, Lee J, Bartholomeusz C, Ueno NT, Xie X: Development of PEA-15 using a potent non-viral vector for therapeutic application in breast cancer. Cancer Lett 2015, 356:374-81.

35. Fiory F, Formisano P, Perruolo G, Beguinot F: Frontiers: PED/PEA-15, a multifunctional protein controlling cell survival and glucose metabolism. Am J Physiol Endocrinol Metab 2009, 297:592-601.

36. Hindupur SK, Balaji SA, Saxena M, Pandey S, Sravan GS, Heda N, Kumar MV, Mukherjee G, Dey D, Rangarajan A: Identification of a novel AMPK-PEA15 axis in the anoikis-resistant growth of mammary cells. Breast Cancer Res 2014,16:420.

37. Soule HD, Vazquez J, Long A, Albert S, Brennan M: A human cell line from a pleural effusion derived from a breast carcinoma. J Natl Cancer Inst 1973, 51:1409-1416.

38. Cailleau R, Young R, Olive $M$, Reeves WJ: Breast tumor cell lines from pleural effusions. J Natl Cancer Inst 1974, 53:661-674. 
39. Pickard MR, Mourtada-Maarabouni M, Williams GT: Long non-coding RNA GAS5 regulates apoptosis in prostate cancer cell lines. Biochim Biophys Acta 2013, 1832:1613-1623.

40. Liang CC, Park AY, Guan JL: In vitro scratch assay: a convenient and inexpensive method for analysis of cell migration in vitro. Nat Protoc 2007, 2:329-33.

41. Cohen PTW, Philp A, Vazquez-Martin C: Protein phosphatase 4-from obscurity to vital functions. FEBS Lett 2005, 579:3278-86.

42. Van Hoof C, Goris J: Phosphatases in apoptosis: to be or not to be, PP2A is in the heart of the question. Biochim Biophys Acta 2003, 1640:97-104.

43.Zhang Q, Claret FX: Phosphatases: The New Brakes for Cancer Development? Enzyme Res 2012, 2012:659649.

44. Chowdhury D, Keogh MC, Ishii H, Peterson CL, Buratowski S, Lieberman J: gamma-H2AX dephosphorylation by protein phosphatase $2 \mathrm{~A}$ facilitates DNA double-strand break repair. Mol Cell 2005, 20:801-809.

45. Mihindukulasuriya, KA, Zhou G, Qin J, Tan TH: Protein Phosphatase 4 Interacts with and Down-regulates Insulin Receptor Substrate 4 following Tumor Necrosis Factor- $\alpha$ Stimulation. J Biol Chem 2004, 279:46588-94.

46. Neviani $P$, Santhanam R, Trotta R, Notari M, Blaser BW, Liu S, Mao $H$, Chang JS, Galietta A, Uttam A, Roy DC, Valtieri M, Bruner-Klisovic R, Caligiuri MA, Bloomfield CD, Marcucci G, Perrotti D: The tumor suppressor PP2A is functionally inactivated in blast crisis CML through the inhibitory activity of the BCR/ABL-regulated SET protein. Cancer Cell 2005, 8:355-68.

47. Sulzmaier F, Opoku-Ansah J, Ramos JW: Phosphorylation is the switch that turns PEA-15 from tumor suppressor to tumor promoter. Small GTPases 2012, 3:173-7.

48. Renganathan $\mathrm{H}$, Vaidyanathan $\mathrm{H}$, Knapinska $\mathrm{A}$, Ramos JW: Phosphorylation of PEA-15 switches its binding specificity from ERK/MAPK to FADD. Biochem J 2005, 390:729-35.

49. Sung JH, Cho EH, Min W, Kim MJ, Kim MO, Jung EJ, Koh PO: Identification of proteins regulated by estradiol in focal cerebral ischemic injury--a proteomics approach. Neurosci Lett 2010, 477:66-71.

50. Hayashi N, Peacock JW, Beraldi E, Zoubeidi A, Gleave ME, Ong CJ: Hsp27 silencing coordinately inhibits proliferation and promotes Fas-induced apoptosis by regulating the PEA-15 molecular switch. Cell Death Differ 2012, 6:990-1002. 
Fig. 1.

PP4c over-expression inhibits cell growth, colony-forming ability, and increases apoptosis of MCF7 cells. MCF7 cells were transfected with pcDNA3.1-PP4c or empty pcDNA3.1. (A) Cellular levels of PP4c are increased in the cells transfected with the PP4c expression construct as determined by western blotting analysis; $\beta$-actin as a loading control. Representative immunoblots are presented to the right of the bar chart. (B) Total and viable cell counts, as determined by flow cytometry, are reduced in cells at $48 \mathrm{~h}$ post-transfection with PP4c. (C) The proportion of apoptotic cells, determined by annexin V staining and flow cytometry, is increased in PP4C transfected cells. (D) Cell cycle analysis revealed that PP4c over-expression reduces the proportions of cells in G1- and S-phases, while increasing the sub-G0 cell count. (E) Clonogenic assay demonstrates that long-term survival of MCF7 cells is compromised after transfection with the PP4c construct; an example image of a clonogenic assay plate after crystal violet staining is to the right of the bar chart. The bar graphs represent means \pm SEM from four independent experiments. ${ }^{*} P<0.05$ versus cells transfected with pcDNA3.1 alone (Student's t test).

\section{Fig. 2.}

PP4C induces apoptosis and inhibits short and long term survival in triplenegative MDA-MB-231 cells. MDA-MB-231 cells were transfected with pcDNA3.1-PP4c or empty vector pcDNA3.1. (A) PP4c protein levels are increased in cells transfected with the PP4c expression construct, as determined at $24 \mathrm{~h}$ post transfection by western blotting analysis; $\beta$-actin as a loading control. Representative immunoblots are presented to the right of the bar chart. (B) Total and viable cell counts, determined by flow cytometry, are decreased in cells transfected with PP4c. (C) The percentage of apoptotic cells, as determined by annexin $V$ staining and flow cytometry, is increased at $48 \mathrm{~h}$ post transfection with PP4c. (D) PP4c over-expression disturbs the cell cycle profile of MDA-MB-231 cells, causes an increase in cell count in the sub-G0 phase and a concomitant decrease in proliferating cells in $\mathrm{G} 1, \mathrm{~S}$ and G2/M phases. (E) Clonogenic activity of MDA-MB-231 is significantly decreased after transfection with PP4C construct. An example image of clonogenic assay plates after crystal violet staining is to the right of the bar chart. The bar graphs represent means \pm SEM from four independent experiments. ${ }^{*} P<0.05$ versus cells transfected with pcDNA3.1 alone (Student's $t$ test).

Fig. 3. 
PP4c-specific siRNAs inhibit basal apoptosis and increase the short and long term survival of MCF7 cells. MCF7 cells were transfected with control (-) siRNA or with PP4c-specific siRNA. Cells were harvested at $72 \mathrm{~h}$ posttransfection, and re-plated for assessment of cell survival after a further $48 \mathrm{~h}$. (A) Expression of PP4c protein levels was determined by western blotting 72 $\mathrm{h}$ after transfection and equivalent loading was demonstrated using anti- $\square-$ actin antibody. Representative immunoblots are presented. (B) Downregulation of PP4C is associated with an increase in total and viable cell numbers, as determined by flow cytometry. (C) The level of basal apoptosis, measured by annexin $\mathrm{V}$ staining and flow cytometry, is decreased in cells transfected with PP4c siRNAs. (D) Cell cycle analysis revealed that PP4C down-regulation affects the cell cycle profile of MCF7 cells, decreases the percentage of cells in sub-G0 and increases the percentage of cells in $S$ and G2/M populations. (E) Colony forming ability is enhanced in the cells transfected with PP4c siRNAs. An example image of clonogenic assay plates is shown on the right. The bar graphs represent means \pm SEM from four independent experiments. ${ }^{*} \mathrm{P}<0.05$ versus cells transfected with (-)siRNA control (one-way ANOVA and Bonferrroni's MCT).

Fig. 4.

siRNA-mediated PP4c knockdown reduces basal apoptosis and enhances the survival of MDA-MB-231 cells. MDA-MB-231 cells were transfected with PP4c-specific siRNAs or negative control (-) siRNA. Cells were harvested at $72 \mathrm{~h}$ post-transfection for protein expression analysis and re-plated for assessment of cell survival after a further $48 \mathrm{~h}$. (A) The protein level of PP4c was determined by western blotting and anti- $\square$-actin was used as a loading control. Representative immunoblots are presented. (B) Down-regulation of PP4c increases total and viable cell counts, as assessed by flow cytometry. (C) PP4c knockdown protects against basal apoptosis, measured by annexin $\mathrm{V}$ staining and flow cytometry. (D) Cell cycle analysis revealed that PP4c down-regulation affects the cell cycle profile of MDA-MB-231 cells, reduces the proportion of cells in sub-G0 and G1 and increases the proportion of cells in $S$ and $G 2 / M$ phases. (E) PP4C down-regulation increases long term survival; a representative clonogenic assay plate is shown on the right. The bar graphs represent means \pm SEM from four independent experiments. ${ }^{*} \mathrm{P}<0.05$ versus cells transfected with (-) siRNA control (one-way ANOVA and Bonferrroni's MCT).

Fig. 5.

PP4c down-regulation enhances the migratory ability of breast cancer cell lines. MCF7 and MDA-MB-231 cells were transfected with PP4c-specific siRNAs or negative control (-) siRNA. Cells were harvested at $72 \mathrm{~h}$ posttransfection for cell migration analysis using the scratch wound healing assay. 
Cell migration is presented as percent wound closure (A) PP4c silencing increases MCF7 cell migration. (B) PP4c silencing also increases MDA-MB231 cell migration. Example images of cells at $36 \mathrm{~h}$ post-wounding are shown on the right of the bar chart. Data are presented as means \pm SEM from four independent experiments. ${ }^{*} \mathrm{P}<0.05$ versus cells transfected with $(-)$ siRNA control (one-way ANOVA and Bonferrroni's MCT).

Fig. 6.

PP4c regulates the phosphorylation state of PEA15 at Ser116. (A) MCF7 and (B) MDA-MB-231 cells were transfected with PP4c-specific siRNAs or negative control (-) siRNA. Cells were harvested at $72 \mathrm{~h}$ post- transfection and the effects of PP4c down-regulation on the phosphorylation of PEA15 was assessed by western Blot analysis using phospho-specific anti-PEA15. Each lane contains $50 \mu \mathrm{g}$ of whole-cell lysate. (A) PP4c down-regulation in MCF7 cells is associated with an increase in the phosphorylation of PEA15 on Ser116. (B) Transfection of MDA-MB-231 with PP4c-specific siRNAs causes a significant increase in the phosphorylation of PEA15 on Ser116. (C) MCF cells were transfected with pcDNA3.1-PP4c or empty pcDNA3.1. The effects of PP4c over-expression on the phosphorylation of PEA15 was assessed after 48h. PP4c up-regulation in MCF7 cells results in a decrease in the phosphorylation of PEA15 on Ser116. Quantification of phosphorylated PEA15 (P-PEA15) was determined by densitometry relative to PEA15 protein and results are expressed as relative percent change compared to control (mock transfected cells). Each bar represents the mean \pm SEM from four independent experiments. Representative immunoblots are shown. ${ }^{*} \mathrm{P}<0.05$ versus cells transfected with (-) siRNA control (one-way ANOVA and Bonferrroni's MCT).

Fig. 7.

PEA15 down-regulation is associated with an increase in apoptosis and a reduction in the viability of MCF7 cells. MCF7 cells were transfected with PEA15-specific siRNAs or negative control (-)siRNA. At $72 \mathrm{~h}$ post transfection, cells were harvested to assess PEA15 protein levels and replated for assessment of cell survival after a further $48 \mathrm{~h}$. (A) Expression of PEA15 protein was determined by western blotting and equivalent loading was demonstrated using anti- $\square \square$ actin antibody. Representative immunoblots are presented. (B) siRNA- mediated silencing of PEA15 reduces viable cell number, as assessed by flow cytometry. (C) siRNA- mediated silencing of PEA15 decreases short term viability. (D) Down-regulation of PEA15 is associated with an increase in the proportion of apoptotic cells, measured by annexin $\mathrm{V}$ staining and flow cytometry. Results are represented as means \pm SEM from four independent experiments. ${ }^{*} \mathrm{P}<0.05$ compared with $(-)$ siRNA transfected cells (one-way ANOVA and Bonferrroni's MCT). 
Fig. 8.

Fig. 9.

Down-regulation of PEA15 abolishes PP4c-mediated loss of cell viability in MCF7 ad MDA-MB-231 breast cancer cell lines. Cells were transfected with PEA15-specific siRNAs to down-regulate PEA15, control cells were transfected with (-)siRNA. At $48 \mathrm{~h}$ post transfection, PEA15 down-regulation was assessed by western blotting (Figure $7 \mathrm{~A}$ and $8 \mathrm{~A}$ ) and then each set of cells was separately transfected with pcDNA3.1-PP4c and pcDNA3.1. Viable cell count was determined by vital dye staining and apoptosis by annexin $V$ and flow cytometry after $48 \mathrm{~h}$. (A) and (B) Over-expression of PP4c in MCF7 cells transfected with (-) siRNA causes a reduction in viable cell number and an increase in apoptosis compared to cells transfected with pCDNA3.1. PEA15 specific siRNAs causes a reduction in MCF7 viable cell number and increase in apoptosis. PP4c over-expression in these cells does not cause additional loss of viable cell number nor an increase in the proportion of apoptotic cells. (C) and (D) MDA-MB-231 cells transfected with specific PEA15 siRNAs shows a significant reduction in viable cell number compared to cells transfected with (-)siRNA. PP4c over-expression results in a reduction in the number of viable cells and increase in the percentage of apoptotic cells in the cells transfected with (-)siRNAs and has no additional effects on the cells transfected with PEA15 siRNAs. Data are presented as the means \pm SEM from four independent experiments. ${ }^{*} \mathrm{P}<0.05$ compared to pcDNA3.1 (one-way ANOVA and Bonferrroni's MCT). 
A $^{\text {Figure(s) }}$

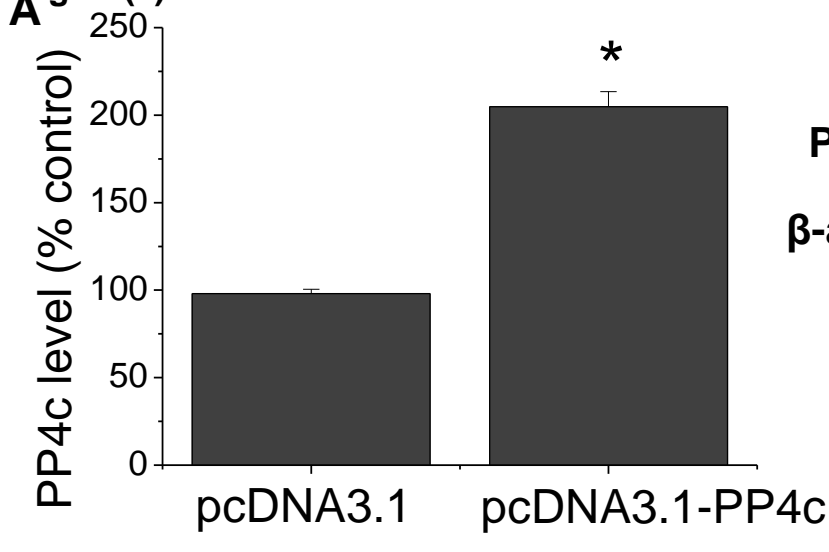

B $\widehat{\bar{\Phi}}, \quad \square$ Total cell count

PP4c

$\beta$-actin

pcDNA3.1 pcDNA3.1-PP4c
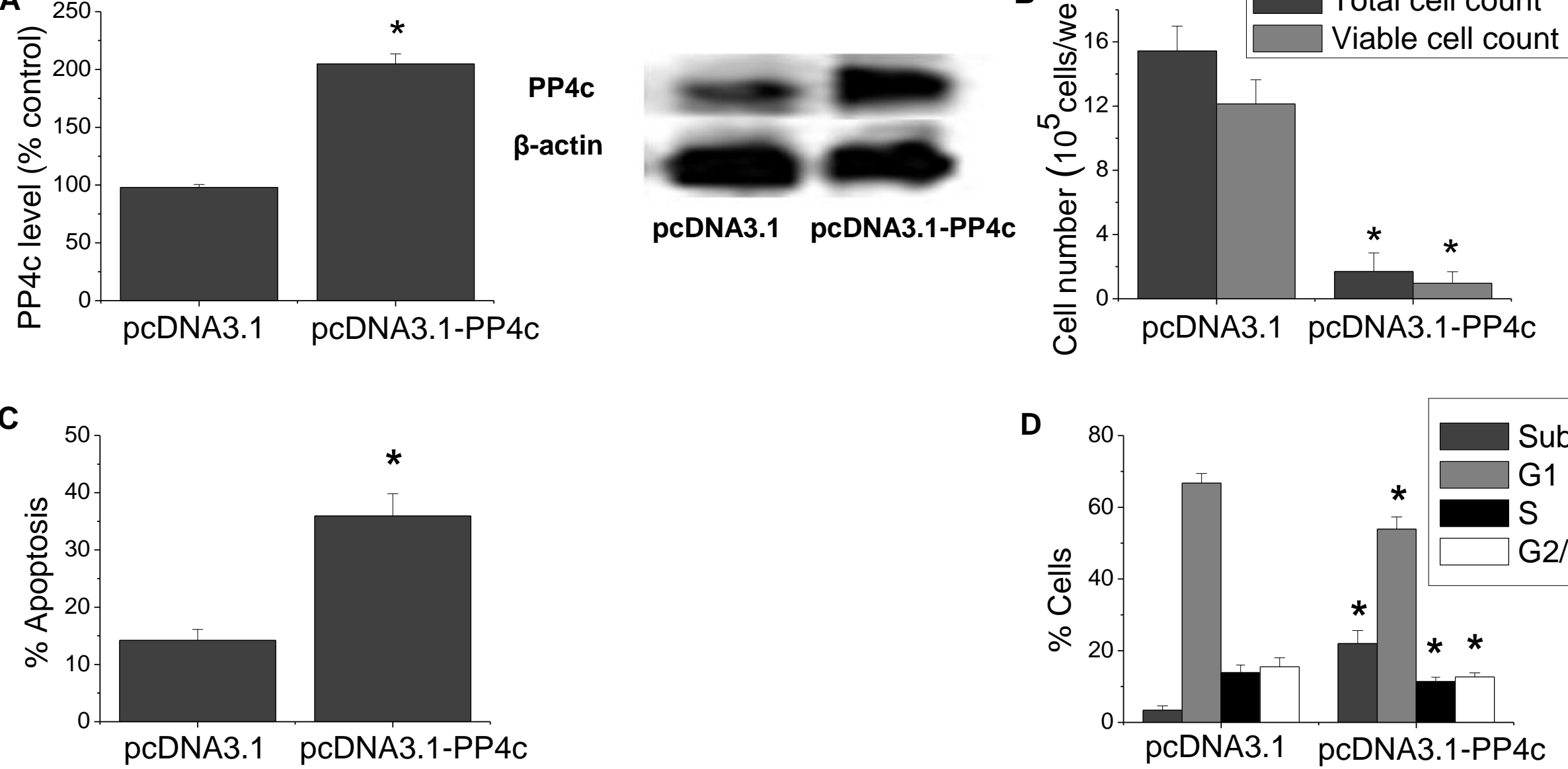

D

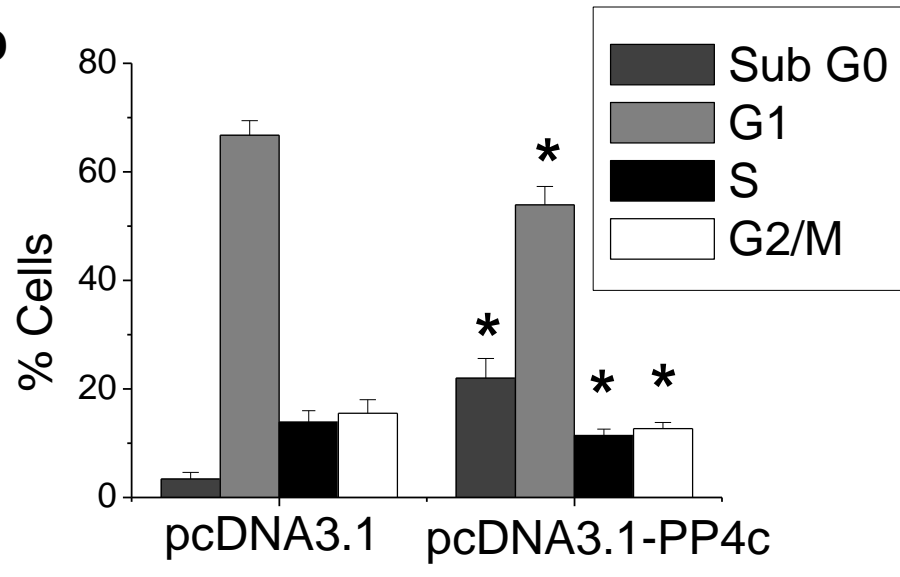

E
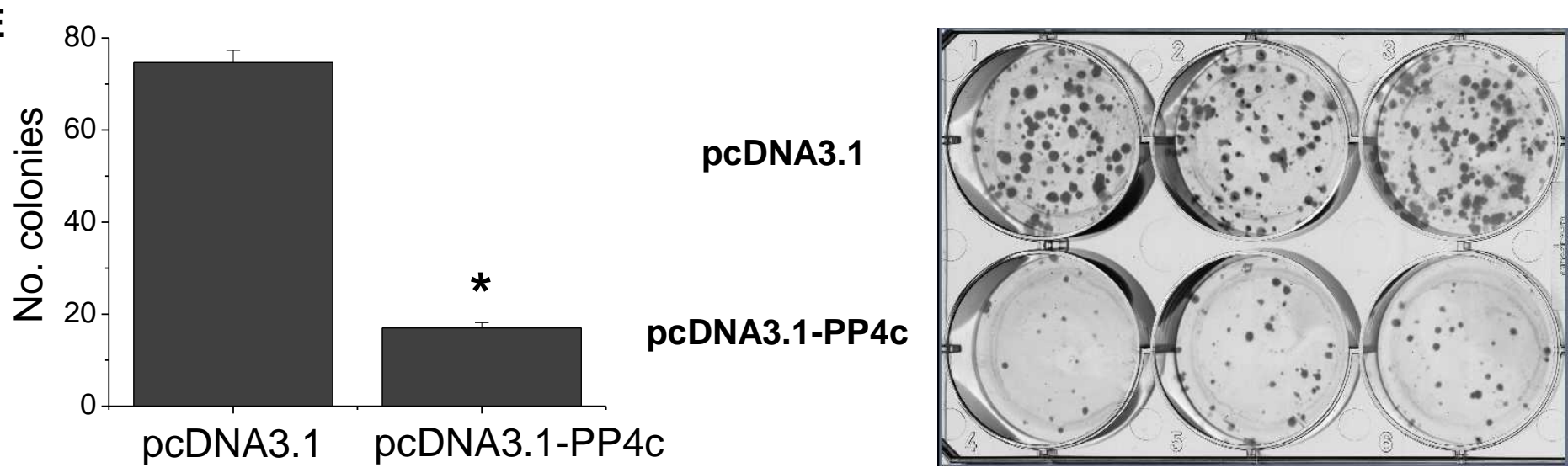
Fiqure(s)

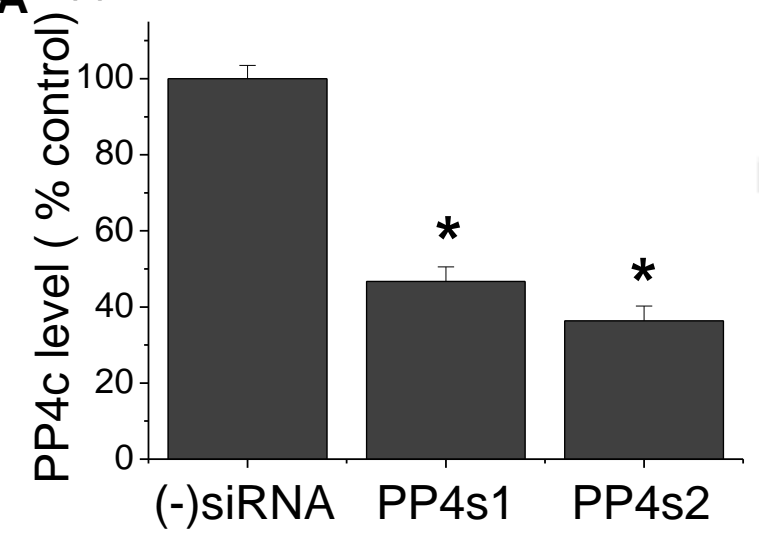

C

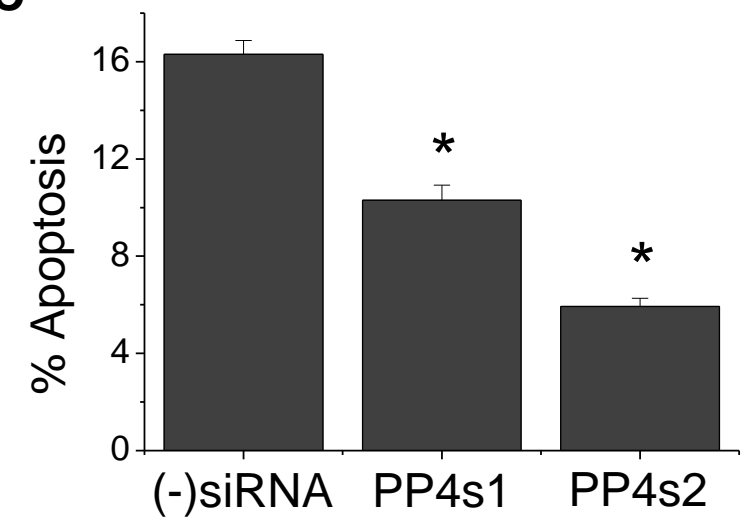

E

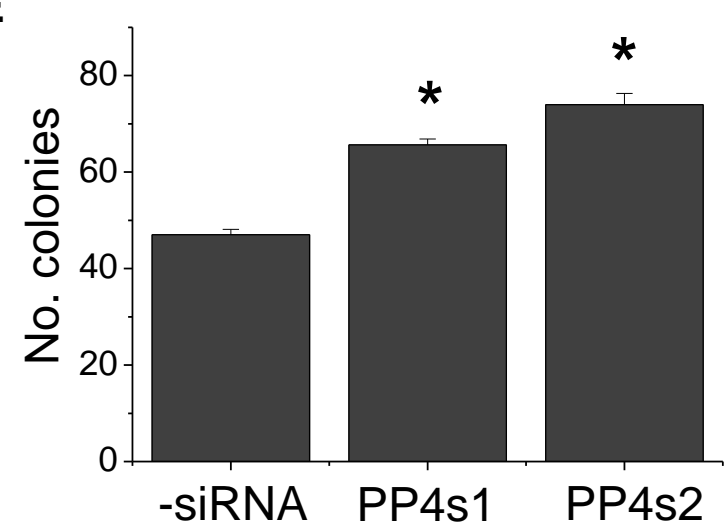

\section{PP4c}

$\beta$-actin

(-)siRnA PP4s1 PP4s2

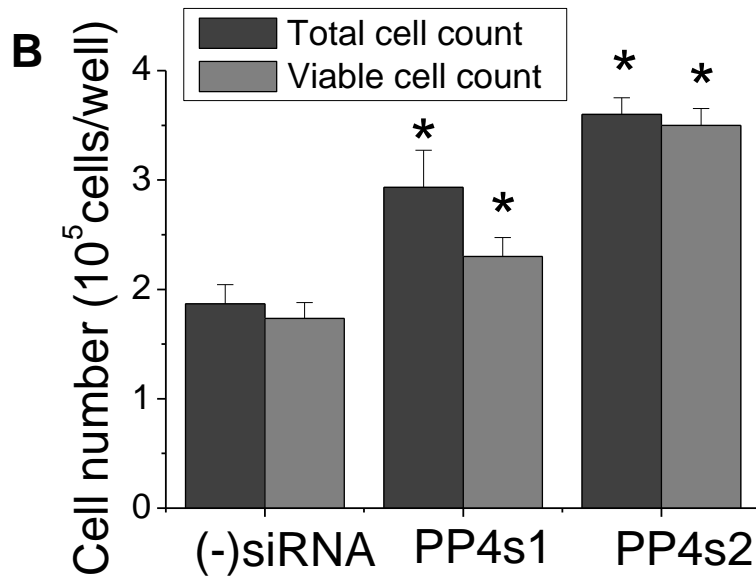

D

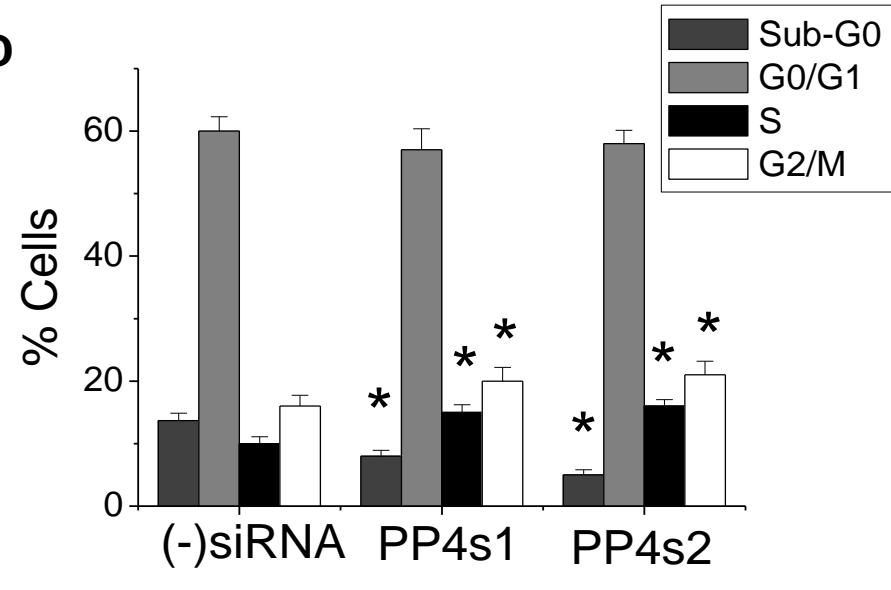

(-)siRNA

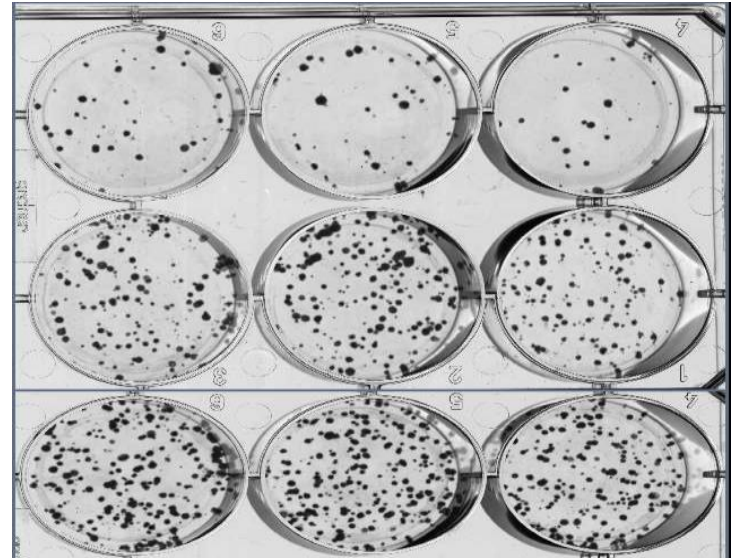

PP4s2

PP4s1 


A

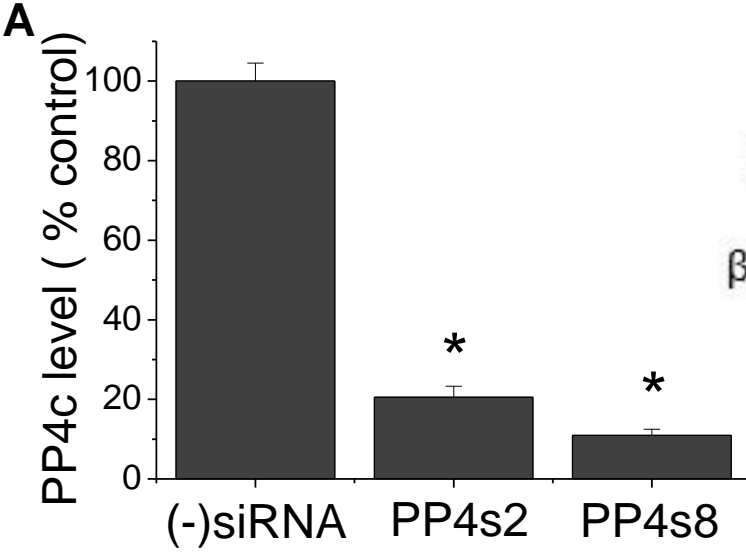

B

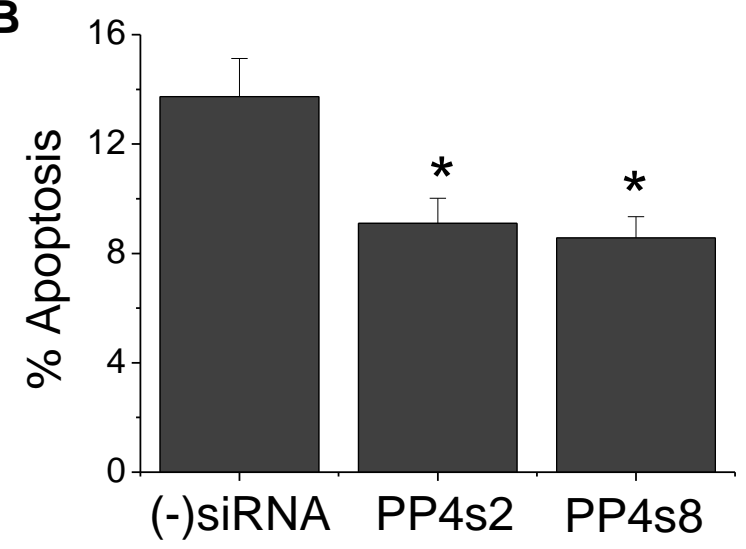

E

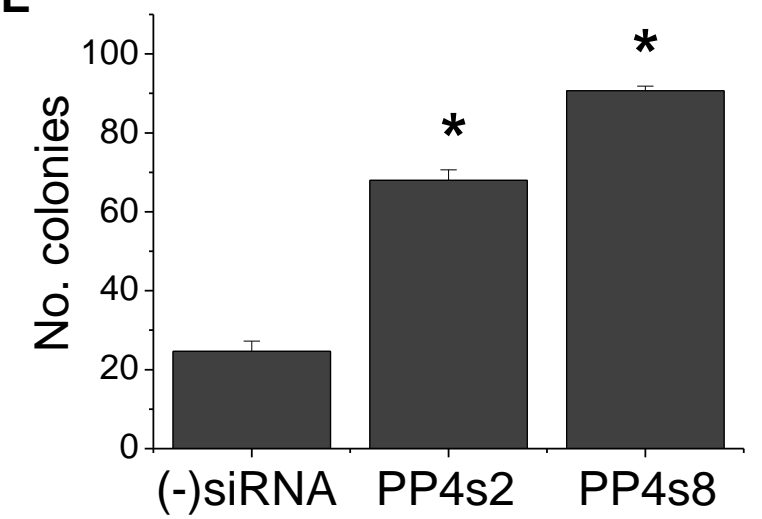

PP4c

$\beta$-actin

(-)siRNA PP4s2 PP4s8

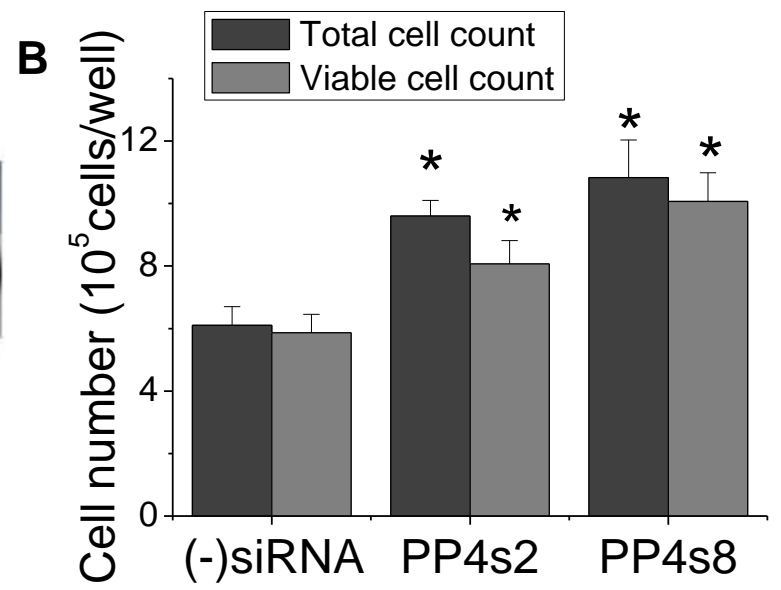

$\mathbf{E}$

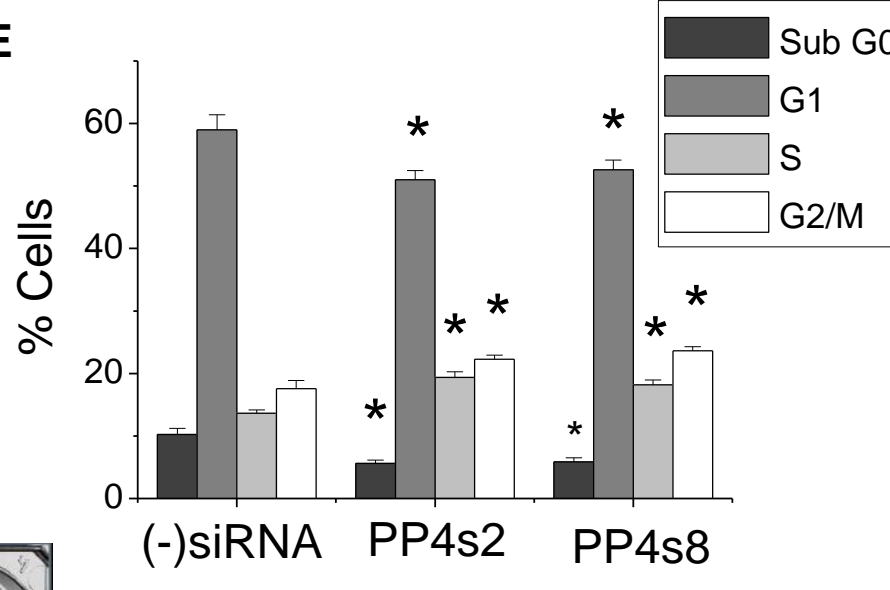

(-)SiRNA

PP4s2

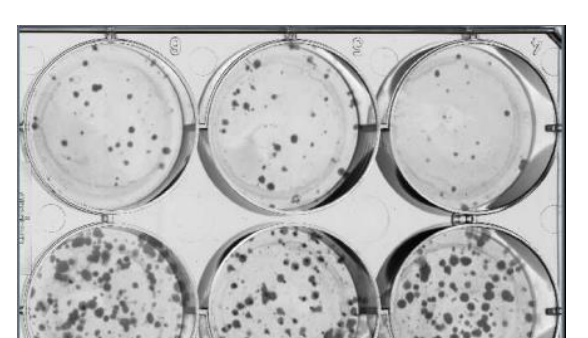

(-)siRNA PP4s2 PP4s8

PP4s8
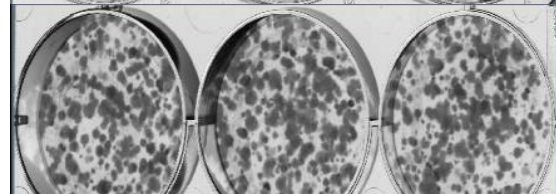

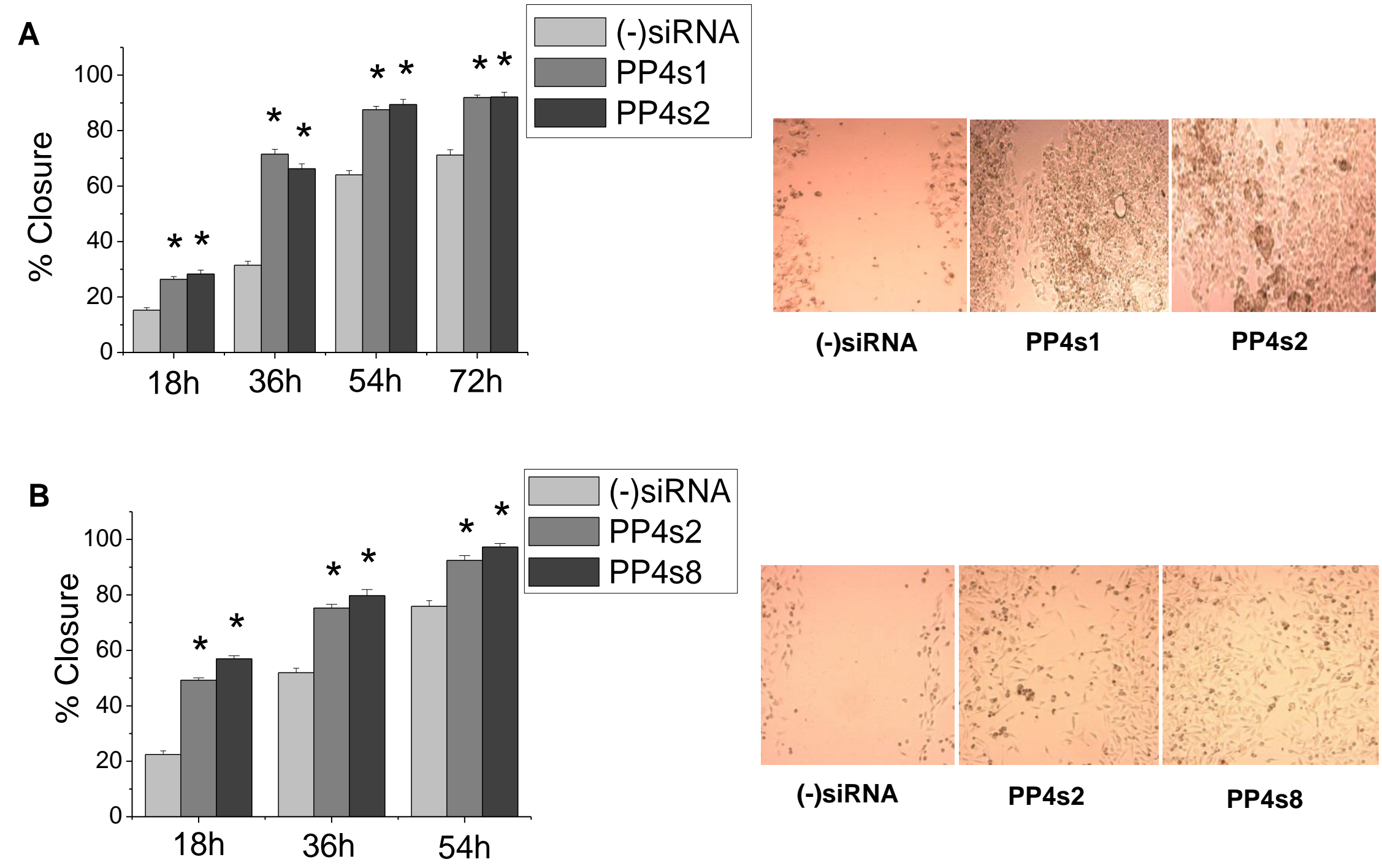


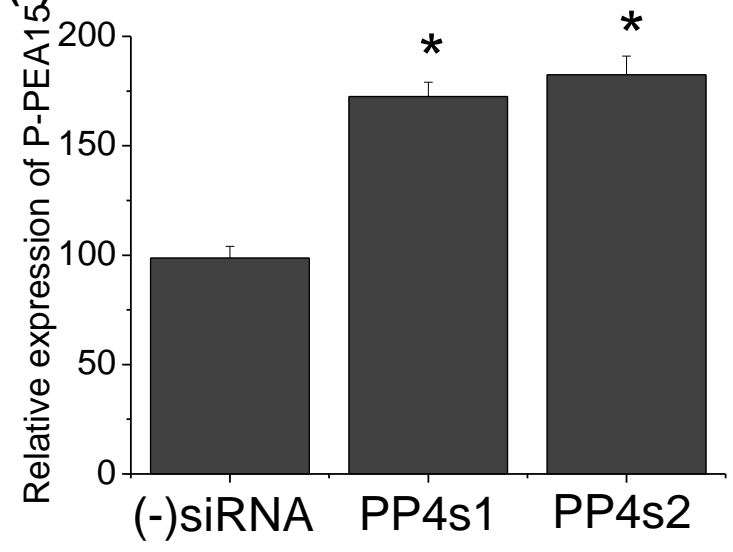

\section{P-PEA15 \\ Total PEA15 \\ $\beta$-actin}

\section{(-)siRNA PP4s1 PP4s2}

B

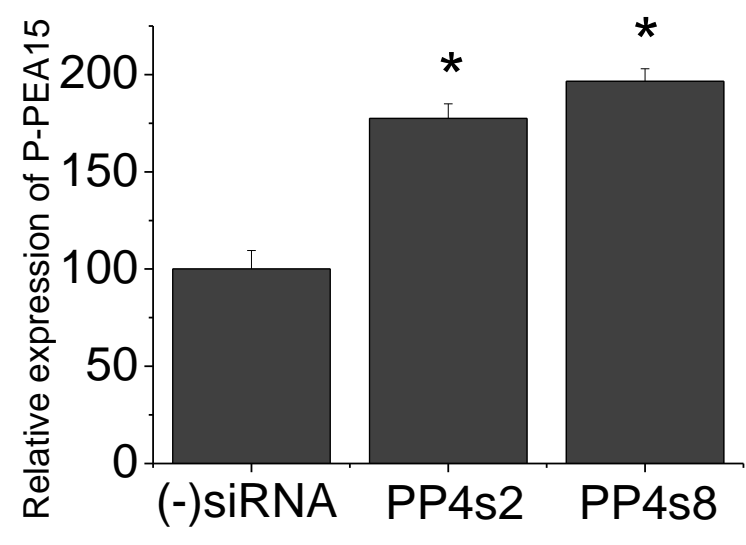

\section{P-PEA15 \\ Total PEA15}

$\beta$-actin

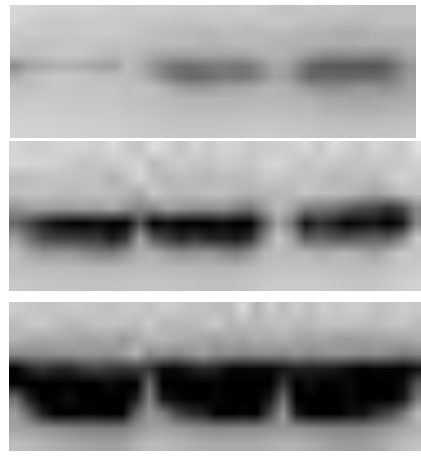

(-)siRNA PP4s2 PP4s8
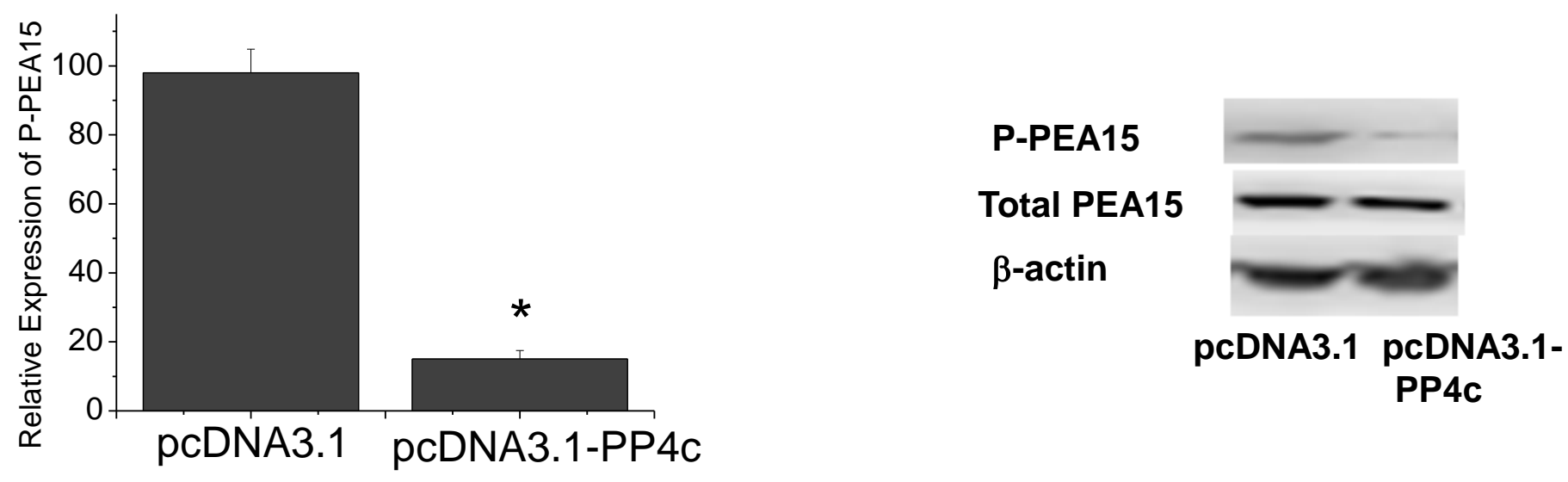
A

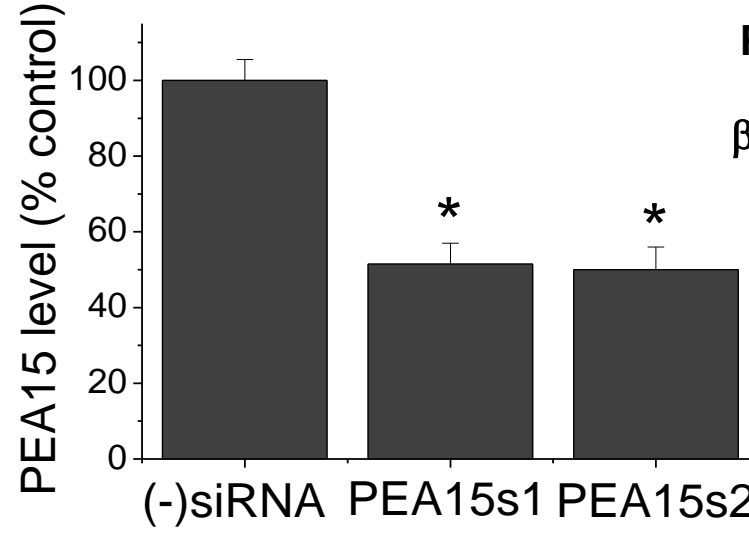

C

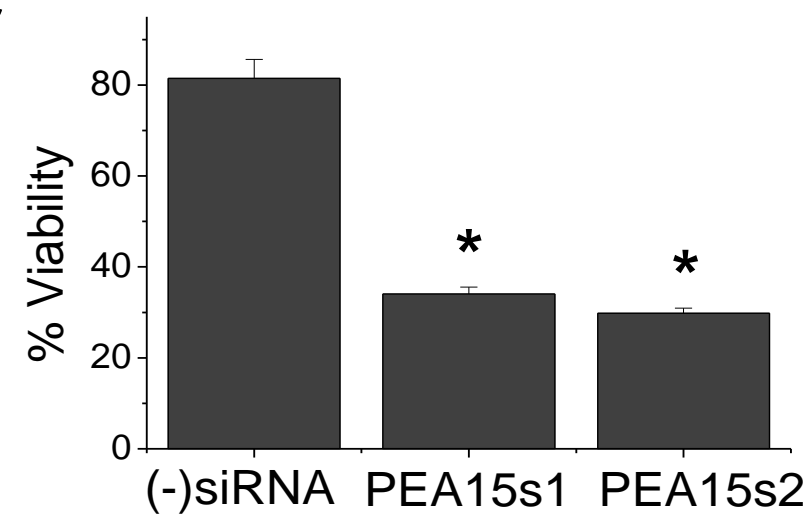

B

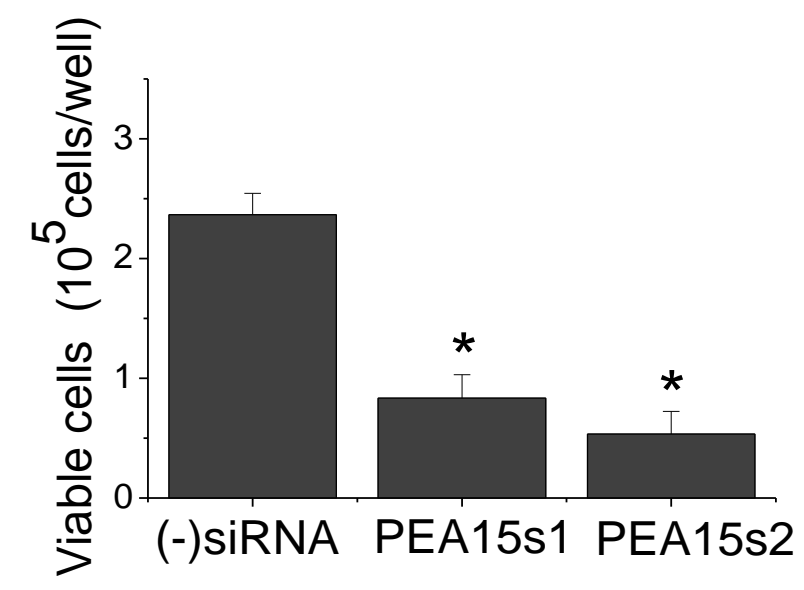

D

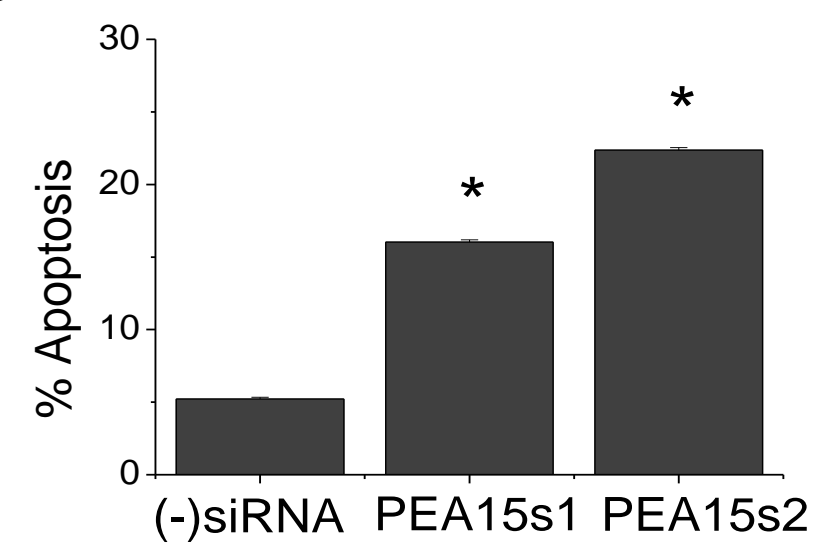



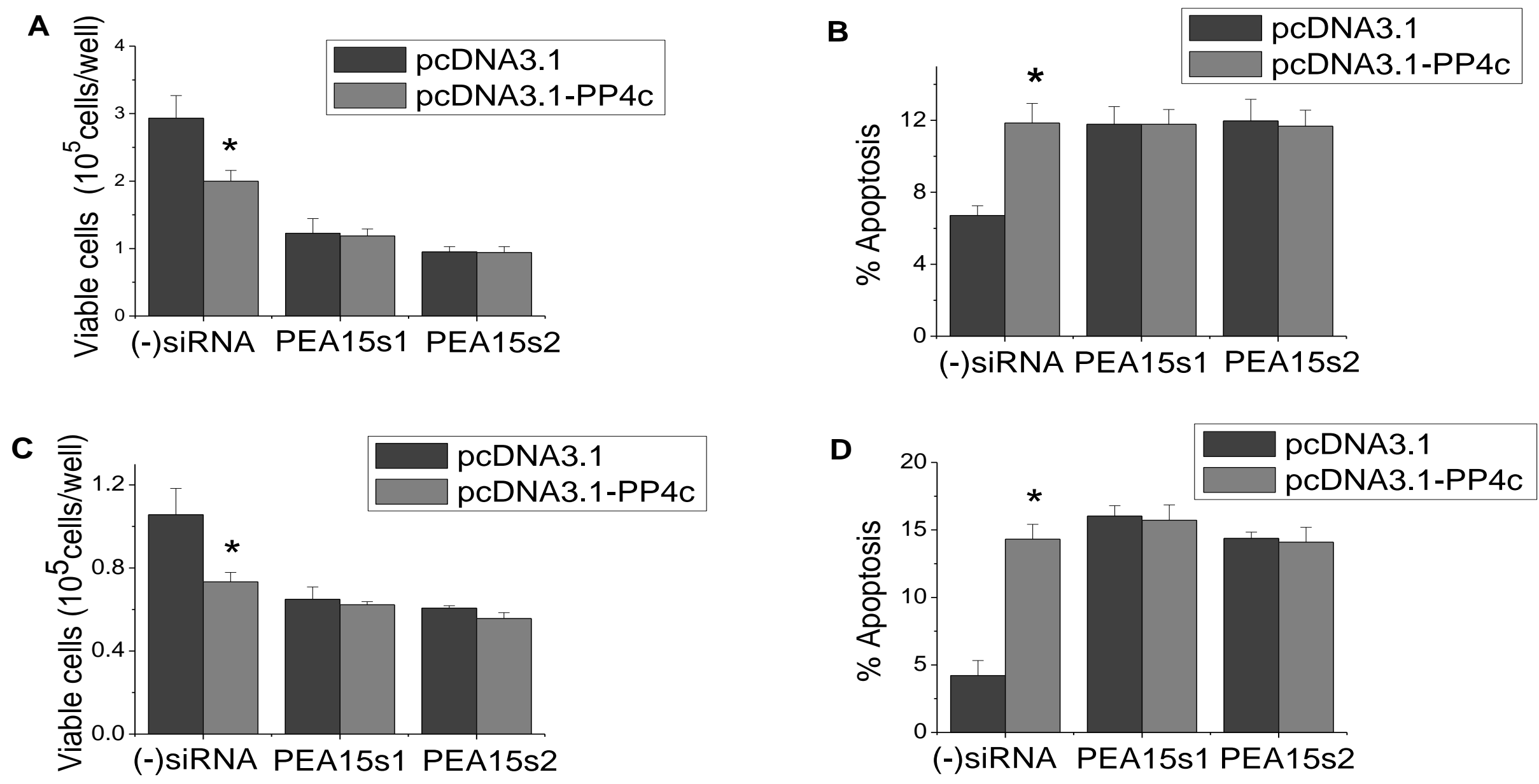
Supplementary Material
Click here to download Supplementary Material: Suplementary materials.docx

Supplementary Material
Click here to download Supplementary Material: Suplementary materials.docx

pup

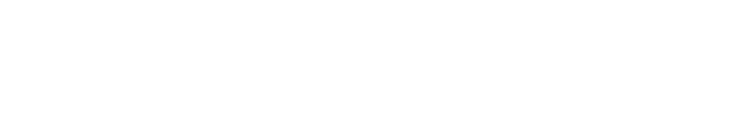

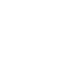

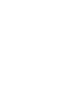
(1) (1) (1) (1) (1) (1) (1) . . . . . . . . . 